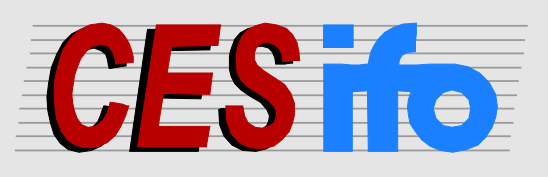

\title{
Working
}

Papers

www.cesifo.org/wp

\section{Efficiency and Environmental Impacts of Electricity Restructuring on Coal-Fired Power Plants}

\author{
H. Ron Chan \\ Harrison Fell \\ Ian Lange \\ Shanjun Li
}
CESIFO WORKING PAPER NO. 4160
CATEGORY 10: ENERGY AND CLIMATE ECONOMICS
MARCH 2013
An electronic version of the paper may be downloaded
- from the SSRN website:
- from the RePEc website:
- from the CESifo website:
www.SSRN.com
Www.RePEc.org
www.CESifo-group.org/wp

\section{CESifo}




\title{
Efficiency and Environmental Impacts of Electricity Restructuring on Coal-Fired Power Plants
}

\begin{abstract}
We investigate the impacts of electricity market restructuring on fuel efficiency, utilization and, new to this area, cost of coal purchases among coal-fired power plants using a panel data set from 1991 to 2005. Our study focuses exclusively on coal-fired power plants and uses panel data covering several years after implementation of restructuring. The estimation compares how investor-owned (IOs) plants in states with restructuring changed their behavior relative to IOs in states without. Our analysis finds that restructuring led to: (1) a two percent improvement in fuel efficiency for IOs, (2) a ten percent decrease in unit cost of heat input, and (3) a lower capacity factor even after adjusting for cross-plant generation re-allocation due to cost reductions. Based on these estimates, back-of-the-envelope calculations find that restructuring has led to about 6.5 million dollars in annual cost savings or nearly 12 percent of operating expenses and up to a 7.6 percent emissions reduction per plant.
\end{abstract}

JEL-Code: L500, Q400, Q500.

Keywords: restructuring, efficiency, cost, utilization, emissions.

\author{
H. Ron Chan \\ Department of Economics \\ University of Maryland \\ College Park / Maryland / USA \\ chan@econ.umd.edu \\ Ian Lange \\ Division of Economics \\ University of Stirling \\ Stirling / United Kingdom \\ i.a.lange@stir.ac.uk
}

\author{
Harrison Fell \\ Division of Economics and Business \\ Colorado School of Mines \\ Golden / Colorado / USA \\ hfell@mines.edu \\ Shanjun Li \\ Dyson School of Applied Economics and \\ Management / Cornell University \\ 424 Warren Hall \\ USA - Ithaca, NY 14853 \\ SL2448@cornell.edu
}




\section{Introduction}

Introducing competitive markets has been perceived, and generally found empirically, as a way to increase efficiency and productivity across a wide spectrum of industries. ${ }^{1}$ As such, during the 1990s all U.S. states and D.C. held hearings considering the move from regulated electricity generation and transmission system, under which so-called cost-of-service (COS) pricing existed, to more competitive electricity markets. The potential benefits and pitfalls of such restructuring have been well studied (e.g., Laffont and Tirole, 1993), but the basic argument in favor of restructuring is quite simple. COS pricing (a form of cost-plus contracting) provides little incentive for integrated electricity companies to become more efficient, while competitive electricity markets should incentivize firms to lower costs of generating electricity. Though the argument for restructuring appears quite straightforward, relatively few states passed and enacted electricity restructuring laws meant to aid in the formation of these competitive markets. This is likely due to, at least in part, the restructuring-induced difficulties experienced in the California electricity market in 2001 (Fowlie, 2010). However, this heterogeneity in electricity market regulations across states, combined with the availability of now several years of data after the implementation of restructuring, presents a suitable setting to empirically analyze the effects of competition on electricity generators. To that end, we analyze the effect of restructuring on fuel efficiency, fuel purchasing behavior, and capacity utilization among coal-fired generating plants using a panel data set from 1991 to 2005 . With estimated impacts on firm behavior, we then provide a first look at the (unintended) environmental impacts of electricity market restructuring.

This study is of course not the first effort to empirically estimate the effects of restructuring on generating firms' behavior. The initial wave of articles testing whether plants have improved their performance after restructuring generally do not include, or had very little, data after restructuring was in effect. For example, Douglas (2006) use data on coal-fired plants from 1981-2000, Fabrizio et al. (2007) used data on fossil-fueled plants from 1981-1999, and Zhang (2007) used data on nuclear plants from 1992-1998. Douglas (2006) finds more efficient plants were dispatched more often when system operators undertook market-oriented reforms. Fabrizio et al. (2007) find that investor-owned plants (IOs) in states that passed

\footnotetext{
${ }^{1}$ For example, see competition impacts on efficiency and productivity in telecommunications from Olley and Pakes (1996), in the concrete industry from Syverson (2004), in natural gas from Davis and Kilian (2011), airlines, railroads.
} 
some form of restructuring legislation reduced their labor and non-fuel operating expenses by three percent compared to IOs in states that did not restructure. However, they do not find any change in the fuel efficiency from restructuring. Zhang (2007) finds an 11 percent reduction in operating costs and seven percent increase in utilization at nuclear plants when states formally move towards electricity market restructuring. Given that they did not have sufficient data after restructuring efforts were implemented, both Fabrizio et al. (2007) and Zhang (2007) argue that anticipation of increase competition led to the resulting changes in firm performance.

Much of the literature that includes data after restructuring was implemented has focused on the impact of the sale of plants. Bushnell and Wolfram (2005) analyze the fuel efficiency and utilization of natural gas and coal plants that were forced to be sold. Using data from 1997 through 2003, they find that divested plants improved their fuel efficiency by two percent. Plants that were subject to restructuring but not divested improved their fuel efficiency by a statistically equivalent amount, implying that the change in incentives under restructuring is the main driver of the fuel efficiency improvement. Further, they find that divested plants reduced their utilization by four percent. Davis and Wolfram (2012) use data on nuclear plant operation from 1970-2009 to determine how divestiture altered operating efficiency. They find restructuring is associated with a 10 percent increase in operating efficiency, largely driven by a reduction in outages. In work concurrent, but independent, to ours, Cicala (2012) uses a matching difference-in-difference estimator to compare the fuel procurement cost of coal and natural gas for divested plants against those that have not been divested. He finds a 12 percent reduction in the cost of coal at divested plants but no corresponding reduction in natural gas prices. He argues that, unlike relatively homogenous and transparently priced natural gas, the heterogeniety of coal quality made it difficult for the public utility commission (PUC) to see the higher prices, thus there was ample room for coal cost reductions when plants were in a more competitive environment. An exception to the focus on divestitures for studies with post-restructuring data can be found in Dean and Savage (2013). They look at how transmission access to a competitive wholesale market and retail competition affect plant efficiency, finding a quite large (nine percent) gain in efficiency for all plants (IOs and non-IOs) in regions with full restructuring (both competitive wholesale and retail markets).

The effects of electricity restructuring have also been studied for markets outside the 
United States. Using data from India, Cropper et al. (2011) find that plant availability increased by a statistically significant level for plants in restructured states, with the largest gain for states that were the first to restructure. They also test for improvements in fuel efficiency but do not find any statistical evidence to support this hypothesis. Looking at England and Wales, which privatized and restructured their joint public utility in 1990, Newbery and Pollitt (1997) find that restructuring is associated with a five percent reduction in the costs of generation. However, they find that most of these benefits from cost reduction flowed to electricity producers at the expense of consumers and the government. ${ }^{2}$

Our study differs from these previous works in several key ways. First, we consider only coal-fired generation plants. Similar to those studies mentioned above that only consider nuclear facilities (Zhang (2007) and Davis and Wolfram (2012)), restricting our sample to coal-fired plants limits confounding factors that could arise from the differences across power generation technologies. Second, as mentioned above, the time span of our data allows us to examine the longer-term impacts of restructuring on coal plants due to the inclusion of several years of post-restructuring observations. This provides a distinct difference from the data used in Fabrizio et al. (2007), which ended near, or even before, the time when many proposed competitive markets were implemented. Third, beyond considering the fuel efficiency and capacity utilization aspects of restructuring, we also test how restructuring affects fuel (i.e., coal) purchasing costs. COS regulation generally made electricity customers the residual claimant of lower coal prices (through a reduction in the price of electricity) or may have imposed other objectives to plant's purchasing decision, such as excessive risk aversion (Borenstein et al. (2012)). Restructured markets makes the generator the residual claimant and remove other potential objectives, thus altering plants incentives when bargaining with a coal mine. As fuel is the largest part of operating expenses, this change in incentives could imply a big rent transfer from coal mines.

We find approximately a two percent improvement in fuel efficiency, measured by the heat rate (Btu of fuel used divided by electricity output), after restructuring among IOs in states that carried out restructuring relative to plants in states without restructuring. When looking at publicly (municipal, state or federal) or cooperatively owned plants (POs), which

\footnotetext{
${ }^{2}$ Beyond the aforementioned studies regarding restructuring-related changes to plant operations, several other studies have examined the possibiliy of market power in the newly created wholesale electricity markets. (e.g., Wolfram (1999),Borenstein et al. (2002),Mansur (2007, 2008), and Hortaçsu and Puller (2008))
} 
often still fall under cost-of-service pricing regardless of the state laws on restructuring, we find no significant difference in heat rates of POs in states with restructuring compared to plants in states without. This suggests that there are no measurable efficiency spillovers from IOs to POs within restructured states. When looking at the restructuring effects on the cost of coal purchases per-unit of heat input, we find that IOs in states with restructured markets had a six to ten percent reduction in per-unit cost of coal purchases compared to plants purchasing coal with similar attributes in regulated states. No statistical significant effect is found for POs' cost of coal purchases. In terms of capacity factors (annual output divided by potential output), we find that restructuring leads to statistically significant reduction among IOs in restructured states. However, at the same time our analysis shows that capacity factors increase as cost of generation decreases. Given that our heat rate and cost of per-unit coal purchases imply reduced costs per megawatt-hours (MWh) for IOs in restructured regions, the results imply that restructuring has two opposing effects on capacity factors. Based on our estimated parameters, the combined effect leads to a decrease in capacity factors for IOs in restructured states. ${ }^{3}$

Performing some back-of-the-envelope calculations, we find that the estimated improvement in fuel efficiency and reduction in cost of coal purchases imply a $\$ 6.5$ million average annual cost saving per plant. Using the U.S. Environmental Protection Agency's Integrated Planning Model assumptions, this would imply an nearly 12 percent reduction in operating expenditures for the average plant in our sample. The improvement in fuel efficiency and change in capacity factors imply average annual emissions reductions of approximately 2300, 1000, and 400,000 metric tons in $\mathrm{SO}_{2}, \mathrm{NO}_{X}$, and $\mathrm{CO}_{2}$ per plant, respectively, if we assume that reduced generation from coal plants is replaced with nuclear generation. If we assume that natural gas replaces the reduced generation in coal, average annual emissions reductions per plant for $\mathrm{SO}_{2}, \mathrm{NO}_{X}$, and $\mathrm{CO}_{2}$ are approximately 2,300, 800, and 243,000 metric tons, respectively. Applying the marginal damages of $\mathrm{SO}_{2}$ calculated in Mueller et al. (2011), the environmental benefit of reduced $\mathrm{SO}_{2}$ emissions from restructuring would be valued at $\$ 5.7$ million per plant per year.

\footnotetext{
${ }^{3}$ This result is in contrast to the strong evidence of increased capacity factor for nuclear plants in restructured states found in Zhang (2007) and Davis and Wolfram (2012). This discrepancy could be explained by the fact that coal-fired power plants have considerably more cycling flexibility than nuclear plants. In addition, given the relatively flat electricity demand during the data period, our finding on coal-fired power plants should not be viewed as being in contradiction with theirs on nuclear plants.
} 
The remainder of the paper is organized as follows. Section 2 provides a brief introduction to the electricity sector and restructuring as well as a literature review. Section 3 presents our empirical models and identification strategy. Data are presented in Section 4 and empirical results are in Section 5. Section 6 concludes.

\subsection{Industry Background}

As noted above, U.S. states have traditionally regulated all stages of the electricity industry as it was perceived that the electricity industry was a natural monopoly. Thus, historically public- or investor-owned firms acted as regulated and vertically integrated monopolies, controlling the generation, transmission, distribution, and retail sectors of the industry. Individual states set the parameters of the regulation with all having some form of COS regulation. Under COS regulation, firms were compensated for operating expenses and a rate of return was allowed for capital costs, subject to state regulators' approval of the firms' transactions. Such a form of cost-plus contracting has often come under criticism for providing poor incentives for efficient investment and operation and prompted moves toward restructuring. ${ }^{4}$

The federal government passed numerous pieces of legislation to accelerate the move to wholesale electricity market competition. In particular, the Energy Policy Act of 1992 opened the door for electricity market restructuring by putting a framework in place that allowed non-discriminatory access to the generation grid, giving rise to greater access for generators unaffiliated with large integrated utilities. This federal action, combined with desire for more efficient generation prompted every state and D.C. to hold hearings on the regulation of their electricity market. Despite the widespread interest in restructuring only 24 states and the District of Columbia (D.C.) passed legislation concerning restructuring and only 15 states and D.C. followed through with implementation. ${ }^{5}$ The forms of the legislations varied across the states that enacted restructuring. However, the states that enacted restructuring legis-

\footnotetext{
${ }^{4}$ Realizing the COS regulation could misalign efficiency incentives, some states also introduced regulations to encourage efficiency within the COS framework. See Knittel (2002) for an analysis of these alternative measures.

${ }^{5}$ Currently only California, Texas, Illinois, Michigan, Ohio, Oregon, Pennsylvania, Delaware, Maryland, New Jersey, New York, Connecticut, Rhode Island, New Hampshire, Maine, and D.C. have formally passed and enacted some form of electricity restructuring legislation.
} 
lation (i.e. the restructured states) generally required a seperation between the generation and transmission/distribution assets of what had been vertically integrated investor-owned utilities in an effort to create more competitive wholesale electricity markets. ${ }^{6}$ Additionally, restructured states enacted changes to the retail side of the electricity market by allowing retail choice, although this was phased in over time in most places and was accompanied by temporary rate freezes in some states to prevent price discrimination by retail electricity providers. The combined changes to wholesale and retail electricity markets in restructured states clearly leave the generating plants in these states to operate in a more competitive environment than those in regulated states.

\section{Empirical Model}

The first goal of the paper is to identify the impacts of electricity market restructuring on the behavior of coal-fired power plants in three important dimensions: fuel efficiency, coal purchasing practice, and capacity utilization. For fuel efficiency, we focus on the heat rate, defined as the Btus per MWh. Fuel input generally accounts for two thirds of the variable cost in coal-fired power plants (Bushnell and Wolfram, 2005). Therefore, the overall efficiency of the plant is largely dictated by the heat rate. In examining coal purchasing practice, we focus on the unit cost of coal procurement (real dollars per million Btus). As we discussed above, restructuring changes how power plants earn their revenue and could give firms more incentives to minimize fuel costs by exploring different contracting practices (contract versus spot) and different coal types (high sulfur versus low) and by improved bargaining. Finally, we examine how the capacity utilization is impacted by the restructuring and how the impact varies across different plants. The ex-ante effects of restructuring on capacity utilization is ambiguous. On the one hand, if restructuring improves efficiency and lowers costs of production among coal-fired plants (more than other types of plants), we would expect

\footnotetext{
${ }^{6}$ For instance, Connecticut required all previously vertically integrated utilities to divest all generation assets, Rhode Island required generation divestiture but allowed transfers to affiliated companies, and Texas did not require explicit divestitures but did require an unbundling of the generation, transmission and distribution, and retail provider functions of the utilities. Regardless of the prescribed divestiture plan, many utilities in states that passed and enacted restructuring legislation did divest all or some of their generation assets to become more retail-sales focused companies. This voluntary divesting of generation assets also occured in a few instances for utilities in regulated states.
} 
these plants to have larger capacity factors since dispatch in a competitive market wholesale market would be based on marginal cost. On the other hand, if the wholesale markets are not competitive, infra-marginal base-load generators, which coal plants typically are, may have incentive to reduce generation in an attempt to increase prices by putting an even higher-cost producer on the margin. In addition, if the restructuring legislation includes payments to plants for excess capacity, as they have throughout the Northeast U.S., then inefficient plants may technically stay in the market and display low capacity factors in order to collect these capacity reserve payments.

\subsection{Model Specification}

Our empirical research design is a difference-in-differences (DD) estimation. The impacts of restructuring are identified through: (1) the fact that some states never undertook restructuring (henceforth, non-restructured states); and (2) the fact that restructuring started in different years in restructured states. In our discussion below, we define the control group to include the coal-fired power plants in non-restructured states and the treatment group to include coal-fired power plants in restructured states, bearing in mind that the temporal variation in treatment adds to the geographic variation for identification of the impacts. We discuss model specification in this subsection and focus on identification challenges in the next subsection.

Heat Reat Let $i$ index a plant and $t$ index time (year). To examine fuel efficiency, we follow the literature such as Fabrizio et al. (2007) and specify the following two-way fixed effect linear regression.

$$
\log \left(\text { HeatRate }_{i t}\right)=\alpha \mathrm{RST}_{i t} \mathrm{IO}_{i t}+\beta \mathrm{RST}_{i t} \mathrm{PO}_{i t}+\mathrm{X}_{i t} \gamma+\delta_{i}+\eta_{t} \mathrm{IO}_{i t}+\xi_{t} \mathrm{PO}_{i t}+\mathrm{u}_{i t}
$$

HeatRate $_{i t}$ is the heat rate at plant $i$ in year $t . \mathrm{RST}_{i t}$ is a dummy variable equal to one if the state where plant $i$ is located is a restructured state and started the restructuring process during or before year $t$ and zero otherwise. In the baseline model, we consider the restructuring process starts with the formal hearing by state legislators as in Fabrizio et al. (2007). This specification allows behavioral changes by power plants in anticipation of restructuring. $\mathrm{IO}_{i t}$ is a dummy variable and equal to one if plant $i$ is an IO plant at year $t$. $\mathrm{PO}_{i t}$ is equal to one if plant $i$ at year $t$ is a $\mathrm{PO}$ plant and zero otherwise. We distinguish the 
restructuring effect between POs and IOs because many POs within regulated states remain primarily vertically integrated utilities that operate under some form of a traditional cost of service regulation. ${ }^{7}$

The model controls for observed time-varying covariates, $\mathrm{X}_{i t}$. It includes a set of timevarying plant characteristics and regulatory environment such as, if the plant has scrubber installed (which is known to negatively affect fuel efficiency), if the plant participates in the first phase of the $\mathrm{SO}_{2}$ permit trading program, if other incentive regulations exist in a state, whether a plant was divested voluntarily in states without restructuring, the logarithm of generation capacity, and the logarithm of output level. ${ }^{8}$ The inclusion of both capacity and the output level variables allows the heat rate to be affected by the size of the plant as well as the utilization rate. The output variable is likely to be endogenous due to simultaneity and we discuss the identification strategy in the next subsection. The regression also includes a full set of plant fixed effects, $\delta_{i}$, to control for time-invariant factors such as the design of a plant that could affect the heat rate. We also include two sets of year fixed effects for IOs and POs to control for plant-invariant factors that affect the heat rate such as technology change, while allowing these factors to impact IOs and POs differently. The idiosyncratic error term is represented by $\mathrm{u}_{i t}$.

Coal Procurement Cost To examine whether restructuring changes power plants' coal procurement cost, we estimate the following price equation

$$
\log \left(\mathrm{UnitHeatCost}_{i t}\right)=\alpha \mathrm{RST}_{i t} \mathrm{IO}_{i t}+\beta \mathrm{RST}_{i t} \mathrm{PO}_{i t}+\mathrm{X}_{i t} \gamma+\delta_{i}+\eta_{t} \mathrm{IO}_{i t}+\xi_{t} \mathrm{PO}_{i t}+\mathrm{u}_{i t} .
$$

UnitHeatCost $_{i t}$ is the per-unit heat cost based on all coal purchased (in dollars per million Btus) by plant $i$ in year $t$. The restructuring and plant dummy variables in this equation are defined similar to those in (1). $\mathrm{X}_{i t}$ in this equation contains some different variables than those in (1). In particular, to control for coal types on unit heat cost, we include sulfur content and ash content (per million Btus) as well as their interactions with dummy

\footnotetext{
${ }^{7}$ For example, the Gibbons Creek power plant in Texas, which is a restructured state, is operated by the Texas Municipal Power Agency (TMPA). TMPA operates as a non-profit municipal utility and is wholly owned by the cities it serves: Bryan, Denton, Garland and Greenville Texas.

${ }^{8}$ As discussed above, some divestiture was forced as part of the restructuring legislation and some was voluntary. Note also, some divestitures occured in states that did not enact restructuring. We do not distinguish among the reasons for restructuring, but rather simply control for this as in other studies.
} 
variables for $\mathrm{SO}_{2}$ permit trading and scrubber installation. $\mathrm{X}_{i t}$ also includes the logarithm of coal quantity purchased (in million Btus) to control for possible volume discount. We treat the quantity purchased as a characteristics of the goods in a hedonic framework and this equation should not be viewed as a demand equation for coal. In addition, the vector of explanatory variables contains the share of coal purchased from the spot market. Most power plants purchase coal from both the spot market (spot coal) and long-term contracts (contract coal). Prices of contract coal are generally higher and with higher sulfur content than spot coal based on the data. The spot share variable is used to control for the difference in the price risk from these two purchasing channels. Both the quantity purchased and the spot share could be endogenous due to simultaneity and the identification is discussed in the next subsection. The additional variables in $\mathrm{X}_{i t}$ also appear in the heat rate equation above: a dummy variable for scrubber, a dummy variable for participation in the first phase of the $\mathrm{SO}_{2}$ permit trading program, and generation capacity. $\mathrm{u}_{i t}$ is the idiosyncratic error term that affects the price of coal purchased such as unobserved coal characteristics.

Capacity Factor The third equation is used to investigate the impact of restructuring on plant utilization:

$$
\log \left(\frac{\text { CapFactor }_{i t}}{1-\text { CapFactor }_{i t}}\right)=\alpha \operatorname{LawPass}_{i t} \mathrm{IO}_{i t}+\beta \mathrm{LawPass}_{i t} \mathrm{PO}_{i t}+\mathrm{X}_{i t} \gamma+\eta_{t} \mathrm{IO}_{i t}+\xi_{t} \mathrm{PO}_{i t}+\mathrm{u}_{i t}
$$

CapFactor $_{i t}$ is the capacity factor of plant $i$ in year $t$. It is defined by the annual output (MWh) divided by the generation capacity (MW) *365*24. The dependent variable, strictly increasing in capacity factor, is defined to have support on both sides of zero. The signs of the coefficient estimates will provide the direction of the partial effects of the explanatory variables on the capacity factor itself. This equation should be viewed as a supply equation and the goal here is to examine how the supply relationship is affected by restructuring.

As we discussed above, restructuring could affect plant utilization through central dispatch where the order is dictated by the marginal cost of production. Thus, before the restructuring was officially under way and the new market emerges, the impact on capacity utilization was likely to be small if it exists at all. Therefore, different from equations (1) and (2), we allow the treatment to start when the restructuring legislation was passed in the benchmark specification and examine more flexible timing mechanisms as robustness checks. The dummy variable, LawPass $i t$ is one if the state where plant $i$ is located is a restructured states and passed the restructuring legislation during or before year $t$ and zero otherwise. 
Among many plant and regulatory variables, $\mathrm{X}_{i t}$ includes the cost of heat input (from coal) per kilowatt-hour (KWh). We include this variable because one would expect that plants with higher operating expenses, which fuel costs account for the vast majority of, would have lower capacity factors (Fabrizio et al., 2007). However, this variable is simultaneously determined with the capacity factor: plants with low operating costs may have higher utilization, but technical features of the plant (e.g., a mechanical failure) may be such that altering capacity factor levels affects operating costs.

Since this equation examines plants' supply conditions, ideally we would like to include wholesale electricity prices (or a representative wholesale prices for plants in vertically integrated utilities that do not operate in a competitive wholesale power market) at which power plants are paid when selling electricity to their customers (e.g., utilities). However, such data are not available publicly. 9 To proxy for a representative wholesale electricity prices in the supply equation, we use capacity factors at the state level for two types of plants: natural gas power plants and fuel oil plants. Generators that primarily use these fuels are generally peak load generators and only turned on during high demand periods due to their marginal costs being higher than base load plants such as nuclear and coal. ${ }^{10}$ The utilization of these peak load plants is likely to be positively correlated with wholesale prices. We also experiment with adding retail prices for industrial customers, which tend to be more contemporaneously tied to current wholesale-market/production-cost conditions, in the equation and obtain very similar results. In addition, we include other plant and regulatory variables in $\mathrm{X}_{i t}$ such as if the plant has scrubber installed, if the plant participates in the first phase of $\mathrm{SO}_{2}$ permit trading program, generation capacity, incentive regulation and voluntary divestiture in regulated states.

\footnotetext{
${ }^{9}$ Monthly average retail rates are available at the state level. However, retail rates are generally not tied directly to contemporaneous wholesale market conditions or contemporaneous marginal production costs, but rather are a function of the utilities' past electricity purchasing and/or production costs. This formation of retail rates varies across state and public utility commission, thus there appears no standard way to get a representative wholesale electricity prices directly from retail rates.

${ }^{10}$ Recently, it appears that low natural gas prices in the U.S. have allowed some natural gas plants to achieve lower marginal costs of production than some coal plants. However, over the period examined in this paper, natural gas prices were relatively high, so it is unlikely that high natural gas plant capacity factors are driven by relative prices over our sample.
} 


\subsection{Identification}

There are a number of concerns in estimating restructuring impacts based on the empirical models outlined above that should be addressed. The first issue has to do with the identification of restructuring effects based on the coefficient estimate on the restructuring dummy variables. The second, as we alluded to above, arises from the potential endogeneity of some of the explanatory variables, which will be empirically important. The third has to do with plant exit in our data. This could lead to a selection bias if less efficient plants are more likely to exit. We discuss these three issues in turn.

Although all three regression equations discussed in the previous section include plant and year fixed effects, the validity of coefficient estimate on the restructuring variable as an estimator of restructuring effect still relies on the exogeneity of the treatment. That is, the timing of restructuring is uncorrelated with the idiosyncratic error term in the three equations: heat rate, unit heat cost of coal purchased, and capacity factor. This assumption could be violated if states choose to initiate the restructuring process in response to timevarying factors that affect these variables at coal-fired power plants. We believe that this violation is unlikely to happen: the driving force behind the restructuring that started in California and states in the Northeast was high historical average costs from uneconomic investments (primarily in nuclear plants) and the political affiliation of the legislature (White, 1996). Thus, the impetus and timing of the legislative process is likely determined by political reasons and rate-of-return elements of COS regulation rather than contemporaneous operational conditional in coal-fired power plants.

A related concern with identifying the impact of restructuring through the coefficient estimate on the restructuring variable is whether trends in the dependent variables before the treatment period were the same across the treatment and control groups. If they are not, we risk interpreting pre-existing differences in time trends as the effect from restructuring. This assumption could be violated if unobserved factors faced by both groups have different effects on the dependent variables across the two groups. Given that treatment and control groups exhibit differences in some characteristics as shown in the data section below, one might be concerned that changes in the dependent variable (due to changes in unobservables) may not be the same in the absence of restructuring. Although this assumption cannot be directly tested, we can take advantage of the data before restructuring to test for differences in pre-existing trends. If pre-restructuring trends in the two groups are similar, this would 
lend support to the assumption that the trends are the same during and post-restructuring. This strategy has been used in previous studies that have data for multiple periods before the treatment (Galiani et al., 2005). The test involves estimating a modified version of equations (1) to (3) where we exclude the first two terms but include separate year dummies for the treatment and control groups. Results of these tests generally do not show pre-existing differences in time trend and are discussed in Section 5.

The second empirical challenge arises from the potential endogeneity in some of the explanatory variables in $\mathrm{X}_{i t}$ in each of the three equations. Equation (1) on the heat rate includes plant output (electricity generation) as one of the explanatory variables. Since the output level and heat rate at a plant are determined at the same time during the course of plant operation, we face an endogeneity issue due to simultaneity. We employ state-level total electricity consumption, gross state product, and housing starts to construct instrumental variables for plant output. State-level electricity consumption reflects electricity demand which would in turn affect plant utilization and output. However, the operating conditions in a particular plant that affect plant efficiency (e.g., unscheduled maintenance) is unlikely to affect state-level electricity demand, which was also used as the IV for plant output in Fabrizio et al. (2007). In the same spirit, we add gross state product and housing starts to capture state-level electricity demand conditions and to increase the explanatory power of the instruments for the endogenous variable. The effect of state-level demand fluctuations on plant output is likely to vary according to plant characteristics, such as if a plant is a base load plant and its size. To capture this, we interact these three variables with statelevel generation profile: the share of coal plant capacity (over total generation capacity in the state). In total, we have six instruments as the full set of instruments. We experiment with using different subsets of the IVs in the regressions. The results, as shown below, are generally robust to the selection. However, the issue of weak IV arises when we use electricity consumption alone.

A similar simultaneity issue exists in the hedonic price equation (2) which relates the unit cost of coal to it attributes. Two of the two explanatory variables (or characteristics of the goods), total coal purchased and the share of coal purchased from the spot market, are simultaneously determined with the dependent variable, the unit price of all coal purchased. That is, the average price can be affected by volume discount and the pricing risk of the spot market (versus the contract), plants' coal purchase decisions including quantity and 
procurement channels are partly determined by prices. To instrument for these two variables, we use the same set of instrumental variables discussed above. These instruments, reflecting state-level electricity demand conditions, should be correlated with total quantity of coal purchased and the spot share but not correlated with the error term in the price equation such as unobserved coal attributes or purchasing contract characteristics.

Equation (3), includes the cost of heat input (from coal) per MWh as one of the explanatory variables. The simultaneity exists because a high unit cost of generation could reduce capacity factor while a high capacity factor could alter fuel efficiency and hence affect heat input cost. Recall that this equation can be viewed as capturing supply conditions, we use the same set of instruments that capture state-level demand conditions. They are unlikely to be correlated with plant idiosyncratic shocks but could affect coal prices (and thus fuel costs per MWh) since power plants are the major buyers of coal. When we use state-level capacity factors for natural gas plants and fuel oil plants to proxy for wholesale electricity prices, we instrument for these two variables as well to control for potential correlation between them and idiosyncratic plant shocks.

The third empirical challenge lies in the fact that power plants may exit the sample due to retirement or missing data. If plant exit is not random, it could lead to selection bias in coefficient estimates. For example, if competition leads to increased probability of exit among inefficient plants, the effect of restructuring on plant efficiency could be overestimated based on observed data. Although previous literature have shown that sample selection could introduce serious bias in other context (Olley and Pakes, 1996), this is not the case in the electricity industry, largely because the small number of exits among power plants. ${ }^{11}$ To check if sample selection could introduce serious bias, we follow their strategy by estimating equations (1) - (3) using a balanced sample of power plants. Similar to their finding, the results from this smaller sample are all very close to those from the full sample.

\footnotetext{
${ }^{11}$ The data show seven boilers which stopped reporting at some point after restructuring took place. The plant's average fuel efficiency was not statistically different after the retirements. Fabrizio et al. (2007) note a similar feature in their data.
} 


\section{Data}

Our data set includes annual plant-level information from 1991 to 2005 gathered from various survey forms from U.S. Energy Information Administration (EIA) and EPA Clean Air Markets Database. We identified coal-fired plants as being plants owning at least one boiler fueled primarily by coal using data in the EIA-860 form. It should be noted that a plant may use more than one type of fuel as plants may have boilers that run off of different fuels. To reduce possible confounding factors that may be present for plants that have ample capacity to switch generation fuel between coal and other fuels, we restrict our sample to those identified as primarily coal plants. The form also gives information on plants' nameplate capacity, which we use to define the capacity variable and in the construction of the capacity factor variable, as well as the plant location (state) and the year the plant came on (from which we derive plant age). We acquire additional plant information from EIA-861, which gives us information on ownership type (IO or PO) on the firms and their respective plants. We also determine whether a plant is required to participate (or join voluntarily from the Opt-in program) in the Acid Rain Program using data from EPA database in Clean Air Markets as well as Table A in the Clean Air Act Title IV. We extract these information to be used as independent variables in our regression analyses.

We derived plant-level coal input use (measured in MMBtu's) and output (generation in MWh) using the EIA-759 form, the EIA-767 form and the EIA-906/920 form. The output variable is defined as the net generation (generation net of the energy used to produce the power) from using coal. The data is extracted from EIA-759 which contains plant-level net generation by fuel type. It was then merged with the EIA-906/920, the successor of the EIA-759 in 2001. EIA originally requires only utilities to file EIA-759 form. Following the first wave of divestitures in 1999, the divested units are required to file EIA-906 instead of EIA-759 which contains the same elements as in EIA-759. We used both forms to determine their net generation depending on their divestiture status. The EIA-767 form gives monthly boiler-level fuel use (in MMBtu) by fuel type and we aggregate to derive the fuel-use variable as the sum of MMBtu's of coal burned at the given plant. ${ }^{12}$ The fuel-use variable is used

\footnotetext{
${ }^{12}$ The EIA-767 form also gives net generation information by boiler but it appears that the EIA-906/920 data, which also collects monthly fuel use and net generation data, appeared to be more complete for 2001 - 2005. Given that the EIA-767 form collects information on many other operational and design attributes, it is possible that some plant operators began only listing fuel use and generation data on the EIA 906/920
} 
along with the output variable to derive the heat rate variable (fuel-use/output). The EIA767 form also contains plant design information of use to our study. Specifically, it identifies whether or not a plant $i$ in year $t$ has a "scrubber" installed, which is used to effectively remove $\mathrm{SO}_{2}$ emissions. We focus our attention at the plant level therefore we ignore any within plant variation in scrubber installations. In other words, Scrubber $_{i t}$ takes the value of 1 if at least one boiler has a scrubber installed. We include this information in the dummy variable Scrubber $_{i t}$ as it affects what types of coal a plant may purchase and possibly affects operational efficiency.

The FERC-423 form collects monthly reports on the fuel purchases, including the heat, ash, and sulfur content of the purchased coal, the origin of the fuel as well as the purchase cost (inclusive of delivery), for each plant-level transaction made by coal-fired power plants in the United States. Given that our other data are of annual observations, we develop a yearly average measure of the relevant variables in the 423 form. We compute a weighted average of the ash and sulfur content using heat content of each transaction as the weight. Analogously, we compute the total cost of coal purchases by summing across all fuel cost multiplied by the respective heat content. Annual per-unit heat prices are formed by dividing total annual fuel costs by total annual heat content. The 423 form also records whether these transactions are done in a spot market or they are contract deliveries. EIA defines a spot purchase as a single shipment of fuel or volumes of fuel purchased for delivery within one year. We compute the share of the spot coal purchases made by each plant, defined as the ratio of heat content of all spot coal purchases to the total heat content of all coal purchases, since it will certainly affect the total cost of coal due to differences in the pricing for spot and contract coal. A concern of using the FERC-423 data is that divested ${ }^{13}$ plants no longer have to file the FERC-423 to report their monthly fuel procurement and this leads to a drop of the observations. ${ }^{14}$ We checked the trends of unit heat cost for those that remain and those that are no longer in our sample. The plot shows that both the trends and levels are not statistically different for the two groups, allaying some of the concerns over the threat

forms. The EIA-767 form is used to recover missing observations (for both input fuel use and net generation).

${ }^{13}$ Information on divestiture is gathered from the Nonutility Depository in EIA-906/920, EIA Electric Power Monthly as well as Non-utility EIA-906 and EIA-423 forms in respective years.

${ }^{14}$ The FERC-423 data that we use was downloaded in 2006. The data available online has since been altered and now reports coal procurement data for an even more restricted set of plants. From 2002 the divested plants have to file EIA-423 but the delivery cost is not released to the public. 
to our identification.

The construction of the restructuring dummy variable $\mathrm{RST}_{i t}$ is defined using the year when hearings on restructuring begin, following the definition used in Fabrizio et al. (2007). However, unlike Fabrizio et al. (2007), we only turn on the restructuring dummy (set the dummy equal to one) for plants that are in states where restructuring actually took place. That is, we acknowledge that there may have been early actions taken by plants who expected restructuring, but we account for the possibility that firms may have known the likelihood of actually deregulating and responded accordingly. For the dummy variable LawPass ${ }_{i t}$, we use the date at which the law passed based on the state-level information provided on the EIA website (www.eia.gov/cneaf/electricity/page/restructuring/restructure_elec.html). In robustness checks we alter the timing of the restructuring effect to more thoroughly examine when restructuring began to impact operation. Following Fabrizio et al. (2007), we only allow plants that have at least three years of observations. Unlike Fabrizio et al. (2007), we did not assign a different plant code for plants with a significant change in capacity, defined as either 15 percent or a $40 \mathrm{MW}$ change to allow a different plant fixed effects for the plant before and after the capacity change in their paper. We postulate that the efficiency gain (as measured in heat rate) due to restructuring can possibly come from the generator installations - by treating these plants using the same plant dummy, we are attributing the efficiency gain (by comparing the deregulated IOs to the control) to the restructuring.

Table 1 gives summary statistics on the key variables that we are using in our analysis. We compare key variables with respect to all observations, restructured IOs), restructured POs, and regulated plants, as shown from Panels (1) to (4). Panels (5) and (6) compare two of our treatment groups (restructured plants) with the control group (regulated plants), conditional on a set of year dummies. Without controlling for other effects such as capacity differences and presence of scrubbers, restructured IOs have slightly lower heat rate, while municipal restructured ones have slightly higher heat rate than the regulated ones.

Figures 1 to 3 plot our dependent variables over time for IOs. Most of these results coincide from what we have seen in the last two panels in Table 1. From Figure 1, heat rate increases (relative to the control group) after 2001 for IOs in both regulated and deregulated states. These results seem to suggest that there is a decrease in fuel efficiency for these restructured plants. However, as briefly mentioned above and as we will see from the next section, when we start controlling for other factors including plant fixed effects, there is 
actually evidence that the fuel efficiency increases for the restructured plants. Figure 2 compares the time trend of the unit cost of coal purchases over time for the two groups. The lines generally follow the same trend: a decrease from 1991 to around 1999 and then increase almost back to 1991 level in 2005. Figure 3 shows capacity factor over time. The IOs in both deregulated and regulated states show an increase in capacity factor over time, while post 2000 the increase for restructured IOs slows down. It seems to suggest that they were operating more intensively before restructuring, than moved to profit maximizing output levels under the introduction of markets. In the next section, regression results on these three outcome variables will be presented by conditioning these changes on the observables like output, age of the plant and generation capacity.

\section{Estimation Results}

\subsection{Plant fuel efficiency}

Table 2 provides estimation results for equation (1) that explores the relationship between restructuring and plant thermal efficiency, as measured inversely by derived annual heat rate values. We report results from nine regressions. All standard errors are clustered at the plant level to allow for serial correlation in the error term. We have also estimated clustered standard errors at the state-year level for all three equations to allow for correlation among plants in the same state in a given year. The results are qualitatively the same and we only report clustered standard errors at the plant level. ${ }^{15}$ The variables that are included in the regressions but not reported in the table are: $\log$ (capacity) and its quadratic term, dummy variables for incentive regulation and divestiture in regulated states, and year fixed effects. Columns 1-7 also include both IO-specific and PO-specific year fixed effects.

The first two columns are from OLS with the first one not including plant fixed effects. The results from the first column suggests that restructuring is associated with 2.1 percent reduction in heat rate (i.e., an improvement in efficiency) for IOs and 3.7 percent increase in heat rate for POs. ${ }^{16}$ By including plant fixed effects, both coefficient estimates are -

\footnotetext{
${ }^{15}$ To obtain clustered standard errors at the state-year level, we use OLS and 2SLS with the full set of plant dummies and year dummies.

${ }^{16}$ Since the equation takes the semi-logarithmic functional form and the restructuring effect is captured by
} 
1.3 but the second one is not statistically significant. The third column, the benchmark specification, is from GMM with the $\log$ (output) variable instrumented using the full set of instruments. The instruments, passing both underidentification and overidentification tests, include $\log$ (state electricity consumption), $\log$ (state gross product), $\log$ (housing starts) and their interactions with the share of state electricity generation capacity from coal. The results suggest that restructuring leads to 1.8 percent reduction in heat rate for IOs. In contrast to Dean and Savage (2013), we find no statitically significant efficiency improvements for POs in states that underwent restructuring. While we do not have statistically significant effects for POs, the point estimates for POs in restructured states is similar to that for IOs. This "noisy zero" results appears to be driven by the plants in Texas. Dropping Texas from the analysis gives us essentially the same estimate on all parameters except for that on $\mathrm{RST}^{*} \mathrm{PO}$, which drops in magnitude to effectively zero. ${ }^{17}$ The coefficient estimate on log(output) implies that a one percent increase in electricity generation in the plant (holding capacity and other variables fixed) would leads to 0.127 percent reduction in heat rate. This is slightly larger in magnitude than the result (0.096) from OLS, suggesting a (weak) positive correlation between the output variable and the error term. Such a correlation may be explained in part through engineering aspects of plant operations. For instance, increasing ambient air temperatures increase electricity demand and thus output, but may also adversely affect plant efficiency (International Energy Agency, 2010).

Columns 4 to 6 employ different sets of instruments to check the robustness and validity of our instruments. Column 4 uses only state electricity consumption as the IV. We fail to reject the null of underidentification, suggesting a weak IV. Neither of the coefficients on IOs and $\log$ (output) is statistically significant. Column 5 adds as an additional IV the interaction between state electricity consumption and the share of state electricity generation capacity from coal. We obtain very similar estimates to those in the benchmark specification given

\footnotetext{
a dummy variable, a consistent estimator for the percentage impact of the dummy regressor on the leveled dependent variable is $\exp (\hat{\alpha}-\operatorname{var}(\hat{\alpha}) / 2)-1$. However, because this estimates are very close to $\hat{\alpha}$ in all our regressions, we instead use $\hat{\alpha}$ in our discussions.

${ }^{17}$ As discussed above, POs in deregulated states still primarily operate under cost of service regulation, so finding no statistically significant change for POs is not surprising. The discrepancy with Dean and Savage (2013), which found large and statistically significant efficiency improvements for POs in states that restructured, may be explained by the fact that their sample starts at 1996, which may alter their differencein-differences estimation relative to results shown here, and they also use a different set of plants than examined here.
} 
by column 3. Column 6 removes the dummy variables on incentive regulation and voluntary divestiture in regulated states. ${ }^{18}$ In column 7 , we focus on the set of plants that stay in the sample throughout the data period (i.e., a balanced panel). Both columns report very similar results to those from column 3. Columns 8 and 9 are from regressions excluding POs to alleviate potential confounding factors. The control group in these regressions includes only IOs in the non-restructured states. The results from these two regressions are very similar to those in columns 2 and 3, their full sample counterparts.

Across GMM specifications, we consistently find that restructuring improves fuel efficiency of IOs for about 2 percent. In all regression, there is no statistically significant and economically meaningful effect for POs. Results in all regressions suggest that a higher output (hence plant utilization) comes with an improved efficiency. The other explanatory variables used in the heat rate regressions do not have statistically significant coefficient estimates in most of the regressions. There is no statistically significant effect from the first phase of the CAA's Acid Rain Program in all regressions. Contrary to expectations, the coefficient estimates on scrubber installation is negative (i.e., efficiency improving) in all GMM regressions but is not significant except in column 1. We do not find significant effect from voluntary divestiture and incentive regulations either. All regressions also include Log(capacity) and its quadratic terms, but the coefficients are never found to be statistically significant except in column 1. We also tried other regressions with various permutations of these variables, as well as specifications with additional and fewer explanatory variables. The results from these specifications are not materially different from those presented here.

To further examine the robustness of our results, we consider several other alternative specifications. The results from three of these specifications are given in 6 . The first specification considered, "LawPass", uses the date the restructuring law passed as the time the RST dummy turns to one. The restructuring effect on fuel efficiency for this specification has approximately the same magnitude as the other specifications presented for this model, but the statistical significance declines. We might expect this if a number of plants in restructured states made efficiency improvements prior to the restructuring law passage. For the second specification, "FRW RST", we exploit the difference in our RST variable and that

\footnotetext{
${ }^{18}$ The data on incentive regulation is based on those used in Zhang (2007) and we thank Fan Zhang for providing us the data. We extrapolated Zhang (2007)'s data to 2005 assuming there's no changes in the incentive programs from 1998.
} 
used in Fabrizio et al. (2007). Fabrizio et al. (2007) label states as restructured as long as a hearing was held and a restructuring legislation was passed but the implementation of the legislation is not necessary. In the "FRW RST" specification, we include another variable FRWRST $_{i t} * \mathrm{IO}$, where FRWRST $_{i t}=1$ after the hearing date in states that Fabrizio et al. (2007) listed as restructured, but did not actually implement restructuring measures. For this specification, we find that the parameter on $\mathrm{RST}^{*} \mathrm{IO}$ is slightly more negative than our other specifications (-0.022 compared to -0.018). We would expect this result if those plants in states that passed some restructuring legislation, but did not implement restructuring provisions, began to implement efficiency improvements in anticipation of restructuring. If those plants did behave in this way, this would raise the average efficiency of the control group in our other specifications and, thereby, lower the magnitude of the parameter on RST*IO. The final specification considered in 6, "East Only", effectively drops all plants west of the Mississippi River in an attempt to create a better control group. For this specification, we find essentially the same restructuring effect as in the geographically more broadly defined specifications.

As discussed above in the literature review, the effect of restructuring on fuel efficiency of power plants, including coal-fired plants, has been examined in Fabrizio et al. (2007) and Bushnell and Wolfram (2005). While the former did not find an effect using data of all power plants from 1981 to 1999, the latter find that divested plants improved their fuel efficiency by two percent based on data of coal and natural gas plants from 1997 to 2003. Our estimates based on coal-fired plants suggest an efficiency gain of about two percent. Since our empirical setup on this equation follows closely with Fabrizio et al. (2007), a discussion is warranted as to why we obtain different results.

First, to check the effect of sample period on the estimation, we restrict our analysis to data from 1991 to 1999. The specification based on column 3 provides a coefficient estimate of $-0.010(0.067)$ on the restructuring dummy, compared with -0.018 based on the full sample. This suggests that within a few years of state hearings on restructuring, some level of efficiency gain has been achieved. Second, to make our specification even closer to Fabrizio et al. (2007), we perform the analysis using the restricted sample and the same instrument, state-level electricity consumption. Similar to what we find using the full sample but a single IV in column 4, we fail to find any significant effect and the underidentification tests points to the problem of weak IV. Additionally, the first-stage t- 
statistic on the instrument is only -0.76. These comparisons suggest that the selection of the instrument might be a cause behind the discrepancy in the finding. We should note though that the issue of weak instrument may not exist in Fabrizio et al. (2007) given that they examine all power plants while our analysis is based solely on coal-fired power plants.

The comparison using the full sample and the subsample from 1991 to 1999 suggests that about the half of the efficiency gain may have been realized within a fews years after the hearing date and point to anticipatory effect as suggested by the literature. To further examine this, we modify equation (1) to examine the time trend of the treatment plants (relative to the control plants) by replacing the restructuring dummy with an interaction term between year dummies and a dummy variable for the treatment plants (e.g., in states that eventually underwent restructuring). Figure 4 plots the regression coefficients on these interactions and the 95 percent confidence interval where we use IOs only to ease exposition (similar pattern holds from the regression with all plants). The coefficient for year 1991 is normalized to be zero. The trend plot suggests that the heat rate among the treatment plants was decreasing over time from -0.02 in 1992 to -0.04 in 1999. But from 1992 to 1994, the coefficients are not statistically significant. This is consistent with the fact that the majority of the restructured states initiated the hearing process in 1994 and 1995 and all started the process by 1998. A puzzling observation from the plot is that the downward trend ended in 1999 and somewhat reversed it after that, especially in 2001. There was a significant spike in natural gas prices in 2001. This may have negatively affected average efficiency levels in deregulated regions by having larger production from coal plants with lower efficiency.

\subsection{Coal Purchases}

Coal is not a homogeneous product, but rather has several key product attributes that affect

price. In addition, coal can also be purchased via spot or contract market which define the purchasing agreement. These different types of purchasing agreements can also affect pricing. Because data on the attributes of coal purchased and the manner in which it was purchased (under contract or via a spot purchase) is available, we can determine whether being in a restructured state has any impact on coal purchase costs. To do this we estimate the hedonic price equation (2).

Table 6 reports results from seven regressions based on equation 2 where the explanatory variables are the characteristics of the coal purchased. The specification breakdowns are 
similar to those in table 2. The variables that are included in the regressions but not reported in the table are: sulfur content of coal purchased, ash content, their interactions with dummy variables of being in phase I of the $\mathrm{SO}_{2}$ permit trading and scrubber installation, $\log$ (capacity) and its quadratic term, dummy variables for incentive regulation and divestiture in regulated states. In addition, all regressions include year fixed effects. Columns 1-5 also allow for separate time trends for IOs and POs as argued in Section 2.

The first column gives the OLS estimation results without plant fixed effects, while column 2 reports the OLS results with plant fixed effects. The first two regressions suggest an inverse relationship between per-unit heat cost and quantity purchased. The coefficient estimate on the spot share in the second regression implies a discount from the spot market, which is counterintuitive. Recognizing that the simultaneity issue exist for both total Btus purchased and the spot share, the third regression is from GMM with the full set of six instruments. The coefficient estimate implies a more negative relationship between unit cost and quantity purchased: one percent increase in total quantity purchased leads to a 0.4 percent drop in unit price. The spot share variable now has a positive and significant coefficient suggesting a price premium from the spot market. This underscores the endogeneity in the spot share variable and the reverse causality is picked up in the OLS regression: when the spot market offers a lower price (e.g., due to random shocks), a larger percentage would be purchased from the spot market.

The key variable of interest, restructuring dummy (RST) interacting with the IO dummy, has positive and statistically significant coefficient estimate in column 1 . The effect becomes zero in column 2 once we controlled for plant fixed effects. In column 3 with GMM, the coefficient estimate suggests that restructuring reduces the unit cost by about 10 percent. This result is consistent with the notion that IO plants in states that have undergone wholesale market restructuring may become more cost-conscious and seek ways to reduce the fuel cost. Column 4 removes dummy variables on incentive regulation and voluntary divestiture in regulated states. Column 5 focuses on the plants that stay in the data throughout the sample period. Columns 7 and 8 are based on IOs only. The qualitative finding that restructuring leads to lower fuel cost is robust across several different GMM specifications and the estimated effect ranges from six percent in column 6 to 13 percent in column 4 .

We do not find a statistically significant effect from the first phase of the $\mathrm{SO}_{2}$ allowance trading program and scrubber installation by themselves in GMM columns. In addition, 
the sulfur content variable has a small and insignificant coefficient estimates across GMM specifications. The ash content variable has a positive and significant coefficient ranging from 0.1 to 0.16 across all specifications. The coefficient estimate on sulfur and ash content may seem counterintuitive as ash and sulfur are often thought to be undesirable characteristics of coal. In addition, the emissions of $\mathrm{SO}_{2}$ from coal plants was regulated in one form or another for many of the plants during the sample period. In particular, the implementation of the $\mathrm{SO}_{2}$ allowance trading program gives a clear cost signal for the emissions of sulfur among participating plants. This would suggest a negative relationship between sulfur content and unit cost. However, the ash and sulfur content are correlated with other characteristics of the coal which we do not control. In particular, they are negatively related to the maturity of the coal and as a result, high ash and sulfur content often means less of other undesired features of coal such volatile matter and moisture that decrease the value of coal (Bellas and Lange, 2007).

However, the coefficient estimate on the interaction between sulfur content and phase I of the $\mathrm{SO}_{2}$ allowance trading program is negative and significant (-0.023 in column 3), suggesting a premium of low sulfur coal among the participants of the permit trading program. The interaction between sulfur content and scrubber installation has a positive and significant coefficient estimate across GMM specifications (0.041 in column 3), implying that plants with scrubbers are willing to pay more for high sulfur coal plants than those without scrubbers.

We perform additional robustness checks and the results from three of them are presented in 6. For the "LawPass" specification, we find the cost-saving effect from restructuring is even larger than those specifications using that turn on the restructuring dummy when state begins to have hearings on restructuring (-0.123 compared to -0.097). We might expect such a result if the cost saving efforts for IO plants in restructured states takes several period, due to, for instance, the unwinding of long term contracts. For the "FRW RST" specification, we find essentially no difference on the RST*IO parameter compared to the similar specification discussed above in 2. This could again be due to the issue of unwinding long term contracts - for plants in states that looked to be headed toward restructuring but did not go through with it, there may not have been sufficient time between restructuring hearings and the realization restructuring was not going to occur for plants to significantly change their contracting positions. Finally, for the "East Only" specification, the cost-saving 
effect of restructuring is smaller in magnitude than for our specifications that consider all of the contiguous states. This may be expected since the eastern plants may not have as many opportunities to switch coal suppliers as western and midwestern plants, which could lower the cost-saving abilities of plants in restructured eastern states.

Across our specifications presented, the estimated parameters consistently imply that restructuring leads to reduction in unit cost of heat input. This could happen if restructuring induces better purchasing practice (e.g., through better bargaining or a better mix of spot and contract purchases). However, as we mentioned above, significant amounts of coal purchased by plants has historically come in the form of long-term contracts. If such contracts were agreed upon prior to the implementation of electricity market restructuring, plants in restructured states might not have been immediately able to respond to the incentives of being the residual claimant induced by competitive wholesale markets. Only when coal contracts are renegotiated could a firm's improved bargaining-power be exercised. In addition, it may take time for firms to learn how to optimize plant operations under restructuring and implement this in their coal procurement negotiations. If such conditions exist, cost-savings in coal purchase price may take time to materialize.

To examine the trend in the reduction in unit cost, we modify equation (2) by replacing the restructuring dummy with the interactions between year dummies and the treatment group dummy. Figure 5 shows the coefficient estimates on these interactions (1992 to 2005). The trend is relative to that for the plants in the control group. There is a clear downward trend from 1997 and the trend continues through 2005 with the exception of 2001 and 2002. In contrast with the plot for heat rate, this plot suggests that changes in coal procurement practice take a longer time to materialize possibly due to existing long-term contracts.

To our knowledge, this results showing that restructuring leads to lower per-unit input prices has not been shown before in the literature and has not been discussed as a possible mechanism by which competitive electricity markets can lower costs. ${ }^{19}$ To further analyze whether restructuring altered plants procurement of fuel, a hedonic price analysis of coal

\footnotetext{
${ }^{19}$ As mentioned above, concurrent and independent work by Cicala (2012) also analyzes the changing nature of coal procurement practices. His work focuses on how being divested affects the price paid for coal. As we note, state-by-state restructuring efforts led to many different rules on divestitures and general reorganization of previously integrated utilities. For that reason, we focus more generally on the role of restructuring in coal procurement practices as opposed to strictly looking at the role of divestiture, providing a distinction between the two.
} 
contract data was undertaken. The EIAs Coal Transportation Rate Database was used to determine whether the price of heat differed for contracts whose vintage is after restructuring legislation was implemented compared to contacts of vintage before restructuring. Contract vintage is either the year the contract was signed, if there had been no renegotiations or the year of the last renegotiation. A restructured vintage dummy variable is created which takes the value of one for contracts whose vintage is after the restructuring legislation was passed and is zero otherwise. This restructured vintage dummy is then interacted with the Btu content of coal in each contract transaction. If plants in a restructured market improved their bargaining position when contracts were being negotiated then the interaction term will be negative and imply a lower cost of heat in those transactions. Results, available from the authors by request, of the hedonic analysis find that the cost of heat in contract whose vintage is after restructuring was statistically smaller than those of a traditional regulation vintage by four percent.

\subsection{Capacity Factor}

Finally, we estimate the effect of restructuring on plant-level capacity factors by estimating equation (3). Different from previous two equations, we specify the treatment to begin when the restructuring laws was passed in the corresponding state because until the various restructuring laws went into effect, plants were still traditionally regulated and thus many of the possible capacity-factor altering incentives may not have taken effect. The restructuring dummy is defined as LawPass $i t$ which is equal to one once the restructuring law was passed in the state.

The a priori expected signs of the parameters associated with the restructuring dummies

are less apparent. Recent studies such as Zhang (2007) and Davis and Wolfram (2012) have found that restructuring, as well as ownership consolidation, has lead to increased capacity factors among U.S. nuclear facilities. This makes intuitive sense as one might expect that competition would force generators to more fully utilize their existing capital. However, base load coal-fired generators in wholesale electricity markets may have incentive to reduce production in order to force higher-cost generators on to the margin, thus reaping the benefits of higher market clearing prices. Evidence of such behavior has been found in several studies (e.g. Wolfram, 1999; Hortaçsu and Puller, 2008; Mansur, 2008). In addition, less efficient plants in wholesale electricity markets may more often get under-bid and thus will be more 
frequently forced out of the market.

Results from nine regressions based on equation (3) are given in Table 5. The first column provides results from an OLS estimation without plant fixed effects while the second column includes planted fixed effects. The coefficient estimate on the restructuring dummy for IOs is negative and statistically significant in column 2, suggesting that restructuring is associated with a reduction in capacity utilization. Since the dependent variable is $\log$ (capacity factor/(1-capacity factor)), the magnitude of this effect is not immediately apparent. ${ }^{20}$ The coefficient estimate on $\log ($ cost per $\mathrm{kWh})$ is negative and statistically significant in both equations, implying a negative correlation between fuel cost and plant utilization. However, as we discussed before, this variable could be endogenous due to simultaneity. The third column reports the GMM results where $\log ($ cost per $\mathrm{kWh})$ is instrumented with the full set of instruments. The coefficient estimate on the cost variable becomes -1.423 compared to -0.769 in column 2, implying the elasticity of capacity factor with respect to cost per $\mathrm{kWh}$ of -0.57 compared to -0.30 for a plant with a 60 percent capacity factor.

The coefficient estimate on the restructuring dummy in column 3 from GMM is very similar to that in column 2 from OLS. In fact, the estimated effect is robust across specifications in columns 2-9. As discussed above, this equation should be viewed as a supply equation and we proxy for wholesale electricity price using state-level capacity factor among natural gas plants and petroleum plants, separately. In an additional regression (not shown in the table), we add state-level electricity prices for industrial customers as another proxy and obtain very similar results. Column 4 removes these two proxies. Column 5 exclude variables on incentive regulation and divestiture in regulated states. Column 6 focuses on plants that stay in the data throughout the data period to check for the effect of plant exit on the results. Column 7 is based on observations with capacity factor above 0.2 (about 200 fewer observations than column 3). Different from most of other coal-fired plants, these plants are most likely peak load generators and their behavior, especially prior to restructuring seems to cause the violation of (pre-treatment) common trend assumption between the control and treatment groups, as shown by the two graphs in figure figure 6 . Columns 8 and 9 focus on IOs only.

\footnotetext{
${ }^{20}$ We can calculate the effect for a given heat rate. For example, for an average plant with a 60 percent capacity factor, the coefficient estimate of 0.301 implies a 12 percent reduction in capacity factor due to restructuring (approximately $0.301 *(1-0.6)$ ).
} 
Across the specifications, we find a 9 to 12 percent reduction in capacity factor for coalfired power plants due to the direct effect of restructuring (i.e. the effect based on the coefficient estimates on the restructuring dummy for IOs alone, all else equal). However, this estimate does not represent the complete effect of restructuring on plant utilization. Our results from the heat rate and unit cost equations suggest that restructuring also decreases heat rate and reduces unit cost of coal, which in turn implies a lower cost per MWh. Meanwhile, our estimates from the capacity factor equation show that a lower generation cost leads to a higher capacity factor, creating a chanel for an indirect effect of restructuring. These results imply a countervailing force on capacity factor through the cost side. The net effect will be analyzed in the next section.

To investigate how the effect of restructuring on capacity utilization plays out over time, we run a regression similar to that in column 9 but replace the restructuring dummy with interaction terms between year dummies and the treatment group dummy. The top figure in figure 6 shows the coefficient estimates on these interactions from 1992 to 2005 for all the observations. There is a continuing downward trend over time and the reduction in capacity factor is statistically significant from 1993, three years before the first restructuring law in 1996. This suggest that there might be pre-existing trend differences between the control and treatment groups, which would lead to over-estimation of the impact from restructuring. We explore this issue further and find, as mentioned above, that this is largely driven by a few peak load plants. The bottom graph in 6 is based on the observations with capacity factor above 0.2. Although the two graphs show similar pattern, there are two important differences. First, the coefficient estimates on interaction terms between year dummies and the treatment group dummy are smaller in magnitude in the bottom graph. Second, the coefficient estimates become statistically significant on a continuous basis only after 1997. It is important to note that the trend depicted by these coefficient estimates should not be viewed as the sole impact of restructuring on capacity factor. For example, figure 5 depicts a continuous reduction in the cost of coal from restructuring, which would counteract the downward trend in capacity factor. 


\section{Cost Savings and Environmental Impacts}

Given the parameters derived from the estimated equations above, we can derive back-ofthe-envelope calculations of cost savings and environmental benefits associated with restructuring. ${ }^{21}$ The calculations are summarized in Table 6 . Note that these values were based on average operation numbers from the last year of our data 2005 and using parameter estimates from specifications that consider IO plants only. More specifically, we use parameter estimates from column 9 of Table 2, column 7 of Table 3, and column 9 of Table 4. The parameter estimates in these IO-only specifications tend to be smaller in magnitude compared to those that use the full sample (IO and PO plants), so our estimates provided here are on the more conservative end. We also made these calculations based on plant operation averages over the span 2001-2005. They were approximately the same as those presented below, so we exclude them for brevity's sake.

We begin with the equations using $\log$ (heat rate) as the dependent variable. From this specification we find that restructuring leads to a 1.7 percent reduction in heat rates when considering IO plants only, which is our more conservative estimate. Based on a sample average heat rate and production values in 2005 for IO plants in deregulated areas of 10,257 Btu/KWh and 5.67 million MWh's, respectively, the 1.7 percent reduction in heat rates leads to an annual savings of approximately 0.90 million million Btu's of coal input per plant. ${ }^{22}$ Using a production-weighted average per-unit coal cost for deregulated plants in 2005 of $\$ 1.51 /$ million Btu, the coal input savings brought about by the deregulation-induced heat rate improvement lead to an average annual per-plant cost savings of about $\$ 1.37$ million. Similarly, the reduced need for coal inputs reduces emission of key pollutants. In percentage terms, emission are reduced by 1.7 percent, since the Btu's of coal needed for a given level of production falls by this amount. To calculate average quantities reduced, we use EPA-published average emission rates of $13 \mathrm{lbs}$ of $\mathrm{SO}_{2}, 6 \mathrm{lbs}$ of $\mathrm{NO}_{X}$, and $2249 \mathrm{lbs}$ of

\footnotetext{
${ }^{21}$ We consider these "back-of-the-envelope" calculations because we do not consider greater general equilibrium effects that would also be associated with restructuring. While not accounting for these general equilibrium effects obviously reduces the accuracy of the results presented below, we believe these cruder calculations are still useful in giving ballpark-estimates of the cost and environmental effects of restructuring for coal plants.

${ }^{22}$ Note the average heat rate is a production-weighted average.
} 
$\mathrm{CO}_{2}$ per MWh of production from a coal plant. ${ }^{23}$ Given these rates, we calculate that the deregulation-induced efficiency improvements lead to per-plant annual emission reductions of 519 metric tons (mt) for $\mathrm{SO}_{2}, 240 \mathrm{mt}$ for $\mathrm{NO}_{X}$, and 89,826 mt for $\mathrm{CO}_{2} \cdot{ }^{24}$

For the coal procurement results, the deregulation effect lowered per million Btu coal costs by 6.4 percent (based on the IO-only GMM results). Given a production-weighted sample average per unit cost of heat $\$ 1.51 /$ million Btu for deregulated plants in 2005 , the annual deregulation-induced reduction in heat-input price for 2005 was approximately $\$ 0.10 /$ million Btu. In 2005, deregulated plants averaged 53.1 million million Btu's of heat input used across our sample. The 2005 per-plant average annual savings from reduced coal-procurement costs brought about by restructuring were approximately $\$ 5.12$ million. The U.S. EPA's Integrated Planning Model estimates that the average plant in our sample would pay $\$ 4$ per MWh for variable operating costs and $\$ 4000$ per MW in fixed operating cost. Using our sample average generation and capacity implies that the average plant has an annual operating expense of $\$ 55$ million in $\$ 2005$. Combining the $\$ 1.37$ million in savings from fuel efficiency improvements and the $\$ 5.12$ million in savings from reduced cost of coal, IOs in restructured states have operating costs that is about 12 percent lower than similar plants under traditional regulation.

Given the form of the dependent variable in the capacity factor equations, the effects of the change in capacity factors due to deregulation are slightly more complicated. Solving equation (3) for CapFactor Cit $_{\text {we }}$ get:

$$
\operatorname{CapFactor}_{i t}=\frac{\exp \left(\alpha \operatorname{LawPass}_{i t} \mathrm{IO}_{i t}+\gamma_{0} \log (\operatorname{cost} \text { per KWh })_{i t}+\widetilde{X}_{i t} \gamma\right)}{1+\exp \left(\alpha \operatorname{LawPass}_{i t} \mathrm{IO}_{i t}+\gamma_{0} \log (\operatorname{cost} \text { per KWh })_{i t}+\widetilde{X}_{i t} \gamma\right)}
$$

where $\widetilde{X}_{i t}$ is a vector of all the remaining right-hand-side terms of equation (3) (including individual and year fixed effects and residuals) and $\gamma$ is the corresponding parameter vector.

As mentioned above, deregulation affects the dependent variable $\ln \left(\frac{\text { CapFactor }_{i t}}{1-\text { CapFactor }_{i t}}\right)$ through

\footnotetext{
${ }^{23}$ These rates are published by the EPA at the website http://www.epa.gov/cleanenergy/energy-andyou/affect/air-emissions.html.

${ }^{24}$ During part of the analysis period used in this study $\mathrm{SO}_{2}$ and $\mathrm{NO}_{X}$ were regulated under cap-and-trade systems. Thus, efficiency improvements, and the later-discussed capacity factor reductions, may not lead to an overall reduction in these pollutants. However, emission permit banking was allowed in the $\mathrm{SO}_{2}$ trading system and the $\mathrm{NO}_{X}$ trading program is only seasonal, so it is possible that the efficiency improvements and/or capacity factor reductions did result in reduced emissions of $\mathrm{SO}_{2}$ and $\mathrm{NO}_{X}$.
} 
two channels in (3) - directly via the deregulation dummy variable (LawPass $i t)$ and indirectly through the $\log ($ cost per $\mathrm{KWh})$ variable. Therefore the marginal effect of deregulation $\left(\right.$ Dereg $\left._{i t}\right)$ on capacity factors' of private firm is given as:

$$
\frac{\partial \text { CapFactor }_{i t}}{\partial \text { Dereg }_{i t}}=\left(\frac{\left(\alpha+\gamma_{0} \frac{\partial \log (\text { cost per KWh })_{i t}}{\partial \text { Dereg }_{i t}}\right) \times}{\left(1+\exp \left(\alpha \operatorname{LawPass}_{i t} \mathrm{IO}_{i t}+\gamma_{0} \log (\operatorname{cost} \text { per KWh })_{i t}+\widetilde{X}_{i t} \gamma\right)\right)^{2}}\right)
$$

Because $\log (\text { cost per KWh })_{i t}=\log (\text { Unit Heat Cost })_{i t}+\log (\text { Heat Rate })_{i t}$, the partial derivative $\frac{\partial \log (\operatorname{cost} \text { per KWh })_{i t}}{\partial \text { Dereg }_{i t}}=\alpha_{U C}+\alpha_{H R}$, where $\alpha_{U C}$ and $\alpha_{H R}$ are the $\alpha$ parameters from equations (2) and (1), respectively. To calculate the average of the marginal effects of deregulation on capacity factors we take a production-weighted average of the calculated $\frac{\partial \text { CapFactor }_{i t}}{\partial \text { Dereg }_{i t}}$ values for private plants in deregulated regions for year 2005. Based on this calculation we find that deregulation reduces capacity factors on average by 0.035 . That is, the direct deregulation effect outweighs the indirect effect of lower production costs brought about by deregulation.

With an average plant output of 5.67 million MWh's in 2005 for IOs in deregulated states, the calculated marginal effect on capacity factor implies deregulation reduced 2005 production from coal plants in deregulated states by an average of 303,162 MWh's per plant. Ignoring the likely small changes in quantity of electrcity demanded due to changes in coal-plant production, the environmental benefits of a reduction in coal-plant generation will depend on what types of generators make up for this lost production. Given the generation profile of restructured states, it seems likely that the reduced coal-fired generation is substituted by generation from nuclear plants, natural gas plants, or some combination of these two. If we assume that effectively emissions-free nuclear plants supplant all the reduced coal-fired generation and using the same emission rates as given above, then the deregulation-induced change in capacity factors for coal plants reduced annual per-plant emissions by an average of $1788 \mathrm{mt}$ of $\mathrm{SO}_{2}, 825 \mathrm{mt}$ of $\mathrm{NO}_{X}$, and 309,352 $\mathrm{mt}$ of $\mathrm{CO}_{2}$. Note that these results imply that if reduced coal-fired generation is replaced with the nuclear generation, the emission savings from deregulation-induced reduction in capacity factors are greater than that from the deregulation-induced improved efficiency.

If instead we assume the reduced coal-fired production was replaced with natural gas-fired generation, then the emissions savings are not as great. For these calculations we assume average emission rates for natural gas plants of $0.1 \mathrm{lbs}$ of $\mathrm{SO}_{2} / \mathrm{MWh}, 1.7 \mathrm{lbs}$ ofNO $\mathrm{N}_{X} / \mathrm{MWh}$, and 1,135 lbs of $\mathrm{CO}_{2} / \mathrm{MWh}$. Based on these emission rates, the effective average annual perplant emissions reductions (i.e., reductions net of emissions from replacing natural gas-fired 
generation) are $1774 \mathrm{mt}$ of $\mathrm{SO}_{2}, 591 \mathrm{mt}$ of $\mathrm{NO}_{X}$, and 153,232 $\mathrm{mt}$ of $\mathrm{CO}_{2}$. While the emission reductions under the natural gas-replacement assumption are not as large as those from the improved efficiency, they still represent sizeable emission reductions. Determining the cost of such reductions, as well as the validity of the replacement assumption, would require a more in-depth market study that is beyond the scope of the current work.

\section{Conclusion}

Starting from mid 1990's, about half of the U.S. states passed legislation to restructure their electricity industry with the goal of reducing electricity costs to ratepayers by increasing competition. In this paper, we provide a further investigation on the impacts of this restructuring. Our study differs from previous literature in the following four aspects: (1) a longer data period than what has been previously used allows us to examine the effects in both the short and medium run; (2) focusing on coal-fired power plants avoids confounding factors from different generation technologies; (3) we examine the impacts on three aspects of plant operation: plant efficiency, utilization, and coal procurement practice; and (4) based on estimation results on plant operations, we quantify the environmental impacts of restructuring.

Our analysis suggests a two percent improvement in the heat rate after restructuring among IOs in states that carried out restructuring relative to IOs in states without restructuring. These figures are consistent with other studies of heat rate such as Bushnell and Wolfram (2005). To our knowledge, this paper is the first to analyze whether coal purchase practice changed as a result of restructuring. We find that the cost of coal purchased on per unit heat basis has decreased among IOs in states with restructured markets by ten percent relative to coal with similar characteristics purchased by plants in cost of service regions. Finally, our results show that restructuring itself lowers capacity factors on the one hand. On the other hand, lower generation costs, which can occur because of deregulation, are associated with higher capacity factors. Based on our sample averages, our estimates show that the net marginal effect of restructuring has led to a reduction of capacity factor for IOs in deregulated regions relative to their cost of service counterparts.

To put our parameter estimates into context, we also calculated per-plant annual savings and emission reductions associated with restructuring. We found, due to deregulation induced efficiency improvements and reductions in per-unit coal costs, IO plants in restructured 
region had an average annual cost savings of $\$ 1.37$ million and $\$ 5.12$ million, respectively. The combined savings are nearly $12 \%$ of an average plants operating expenses. Both efficiency improvement and reduction in capacity factor in coal-fired power plants lead to emissions reductions. Depending on how much the generation from coal-fired plants are replace by natural gas or nuclear plants, the emissions reduction are likely to be in the range of 2,293-2,307 $\mathrm{mt}$ for $\mathrm{SO}_{2}$ (7.5-7.6 percent), 831-1,065 mt for $\mathrm{NO}_{X}$ (5.9-7.6 percent), and 399,178-243,058 mt for $\mathrm{CO}_{2}$ (4.6-7.6 percent).

While our study contributes to the literature by bringing new evidence to bear, it also points to several directions for future research. First, it would be interesting to further investigate the importance of market power in the change of capacity factors after restructuring. Second, whether these results can be generalized to other power plants such as natural gas power plants should be addressed in the future. Third, what has been the impact of increased bargaining power by plants for coal on coal mines, if indeed this is the cause of the lower coal purchasing costs we find? Fourth, has electricity restructuring reduced the environmental impact of coal plants? Improved efficiency would suggest that it has, but the reduction in costs may more than offset the efficiency gain. A more complete general equilibrium analysis is required to fully understand these tradeoffs. Finally, the empirical literature including this analysis, do not analyze the effect of restructuring on investment, adoption of new technologies or entry and exit. The impact of restructuring on these important factors remains to be examined.

\section{Acknowledgements}

We thank Kathy Baylis, Matthew Chesnes, Dave Evans and seminar participants at Cornell University, University of Colorado-Denver, University of California-Berkeley, University of California-San Diego, University of Maryland, 10th Annual International IO Conference, 14th Annual CU Environmental and Resource Economics Workshop, CESifo Energy and Climate Economics Conference for helpful comments. All errors are our own. This research was partially funded by the Environmental Protection Agency under EPA agreement number PI -83425801-0. 
Figure 1: Plot of Heat Rate over time

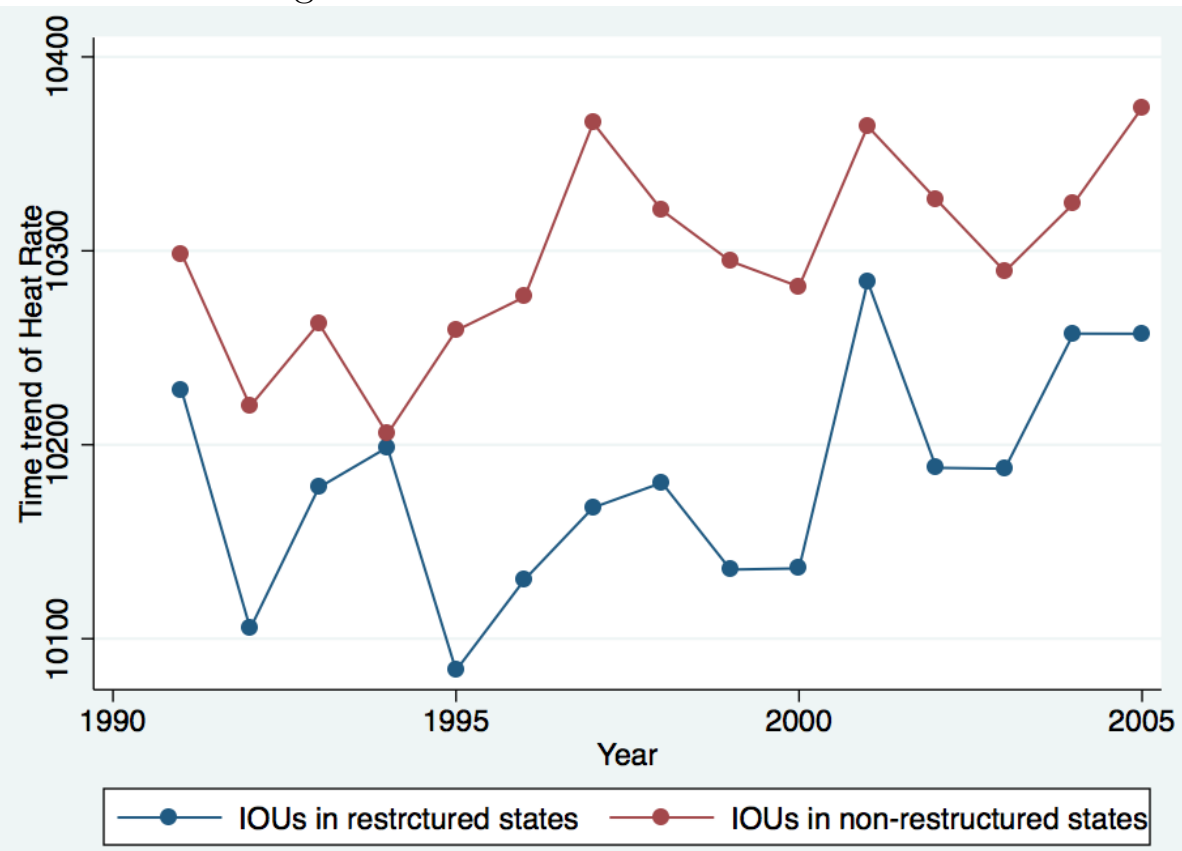


Figure 2: Plot of Unit Heat Cost over time

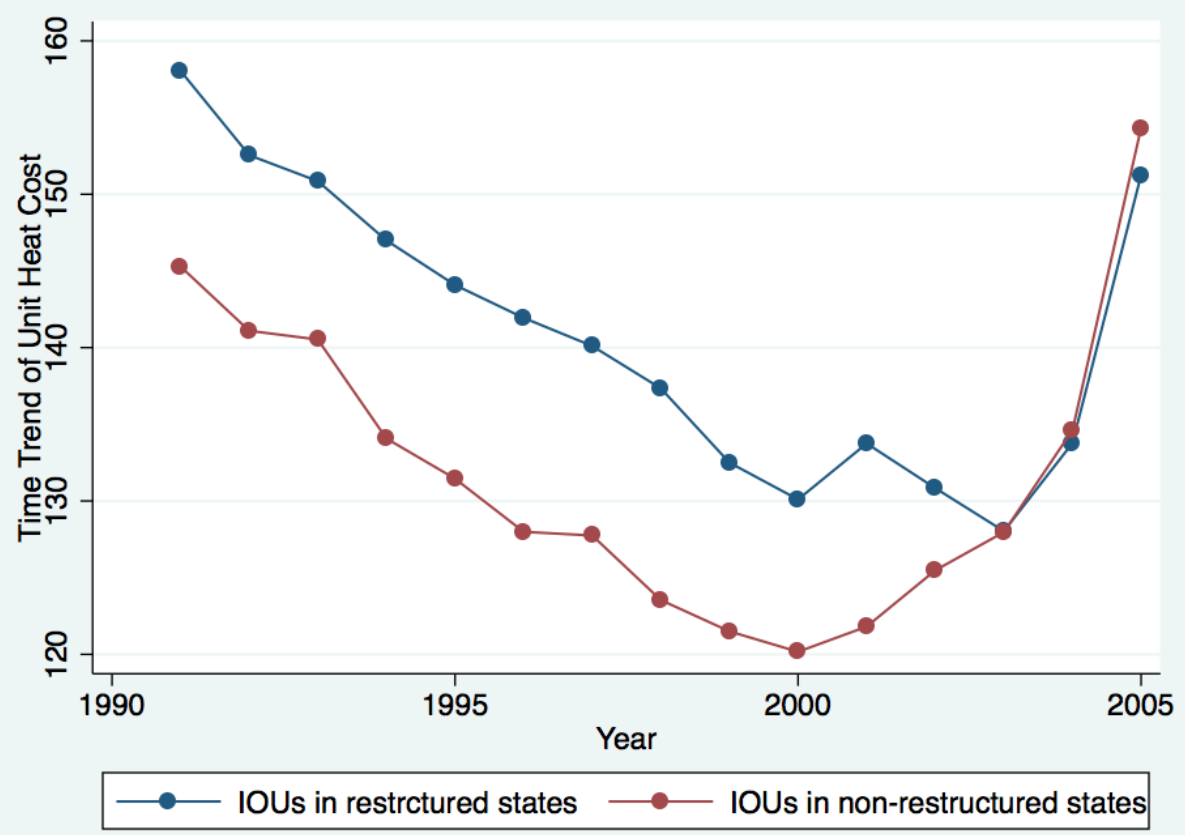


Figure 3: Plot of Capacity Factor over time

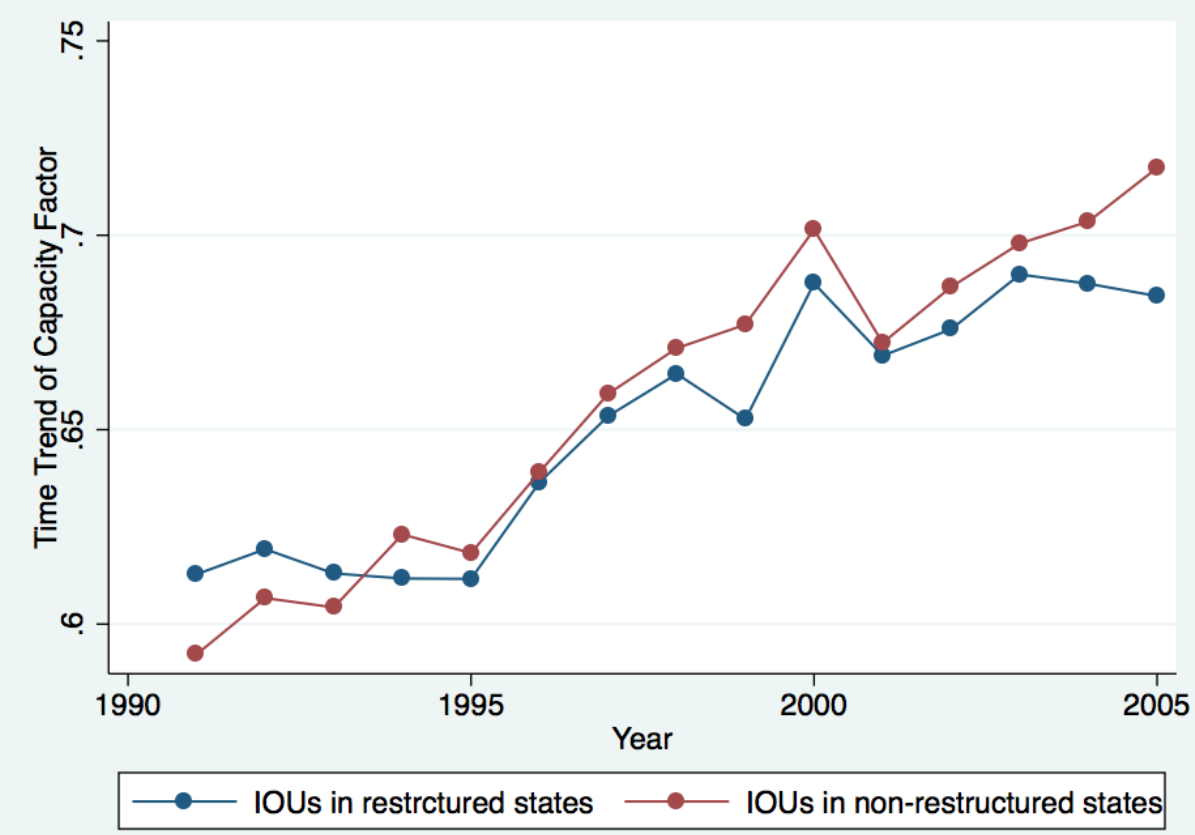


Figure 4: Time Trend of Heat Rate in Treatment Group

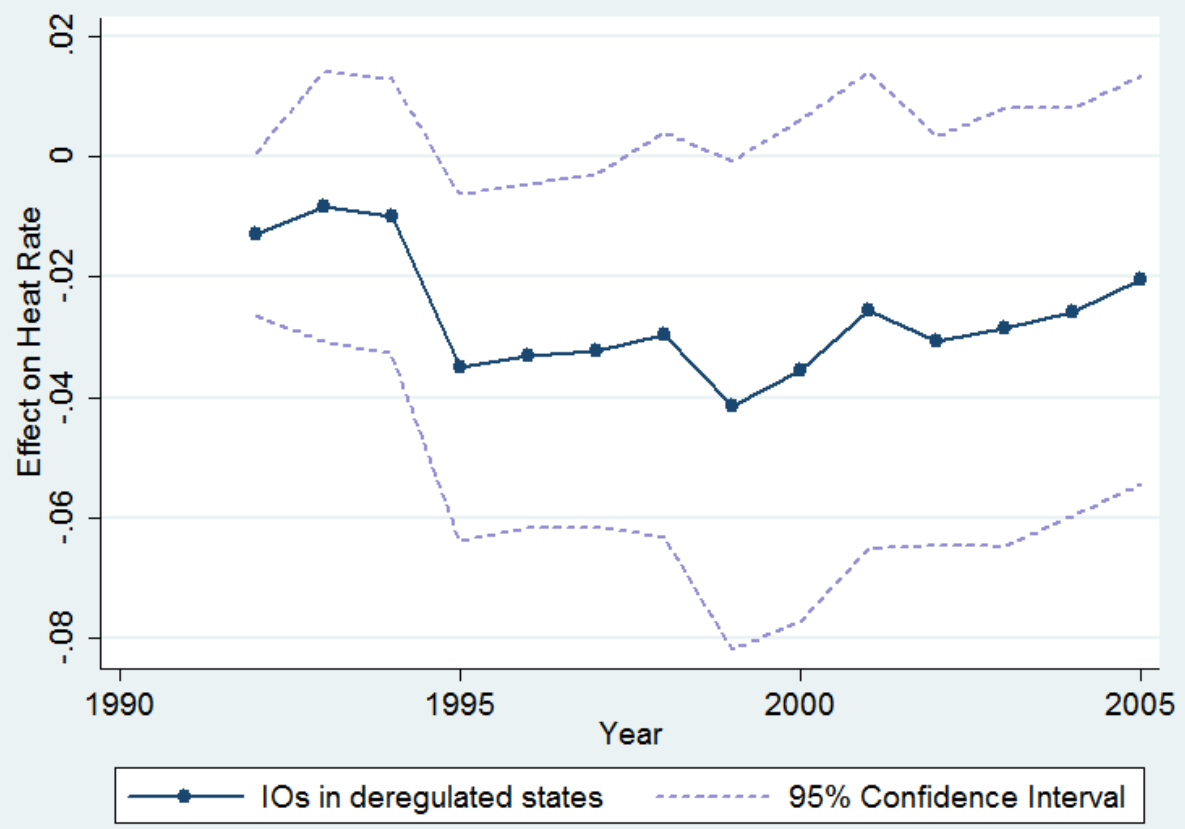


Figure 5: Time trend of Unit Heat Cost in Treatment Group

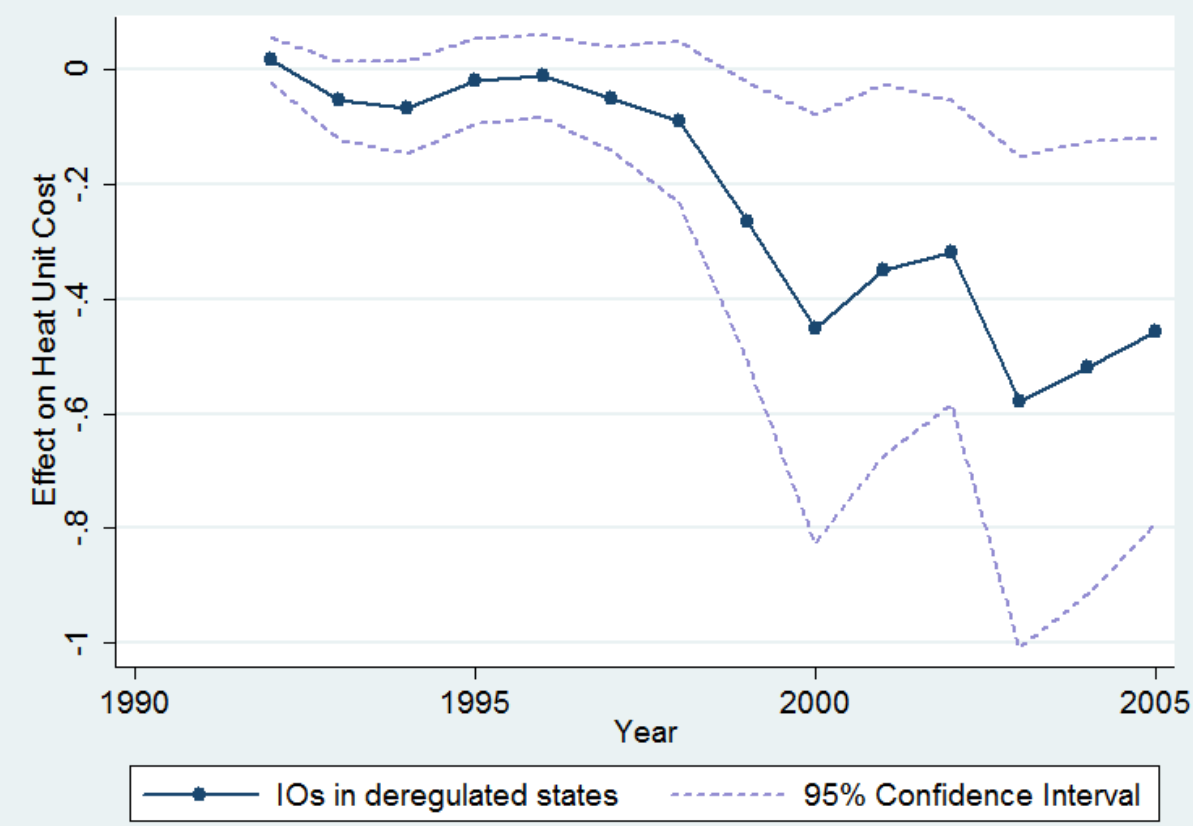


Figure 6: Time Trend of Capacity Factor/(1-Capacity Factor) in Treatment Group
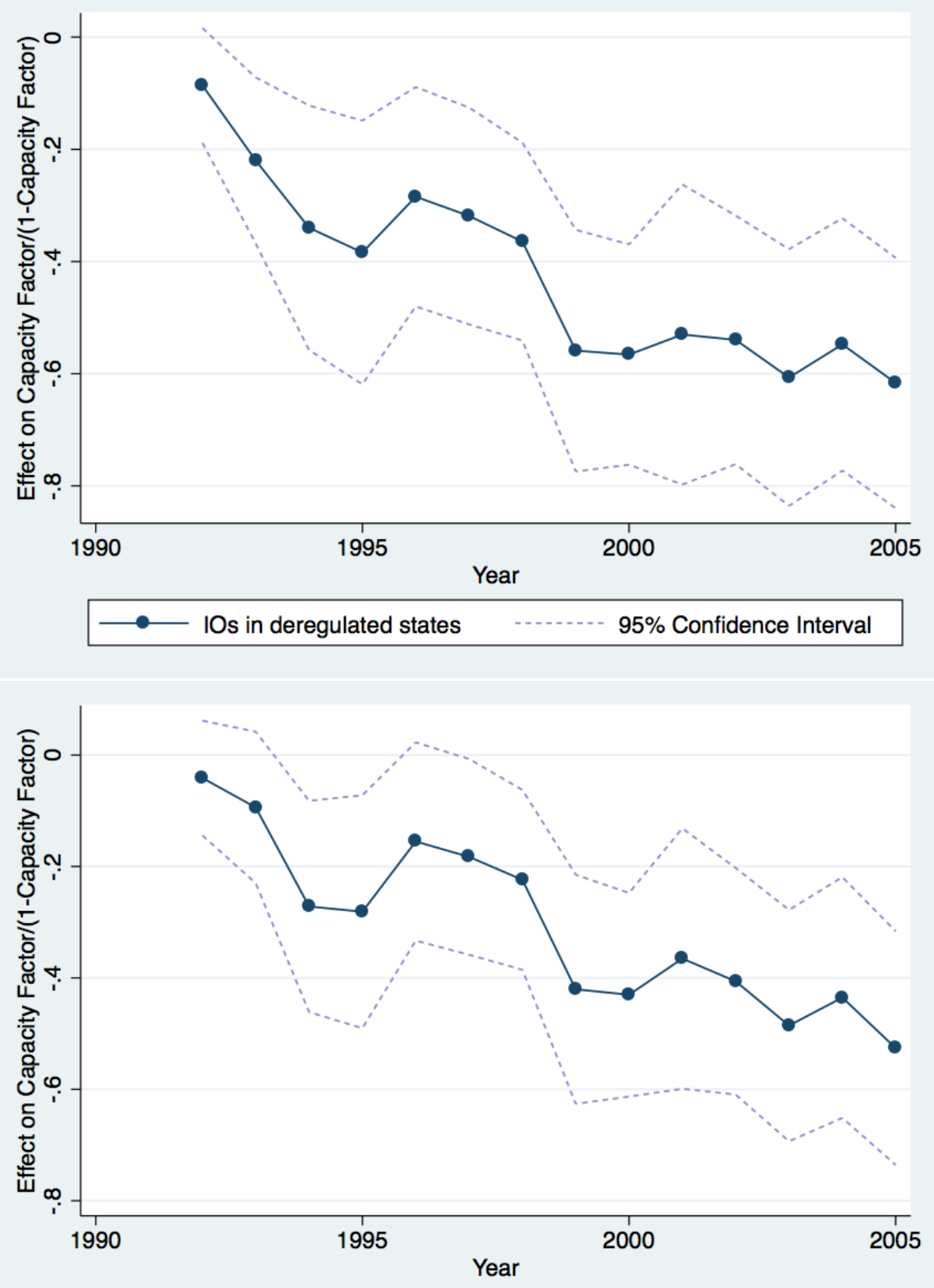

IOs in deregulated states

95\% Confidence Interval

Note: The top figure is base on the full sample while the bottom one is based on a restricted sample with capacity factor larger than 0.2 (about 200 observations less). 


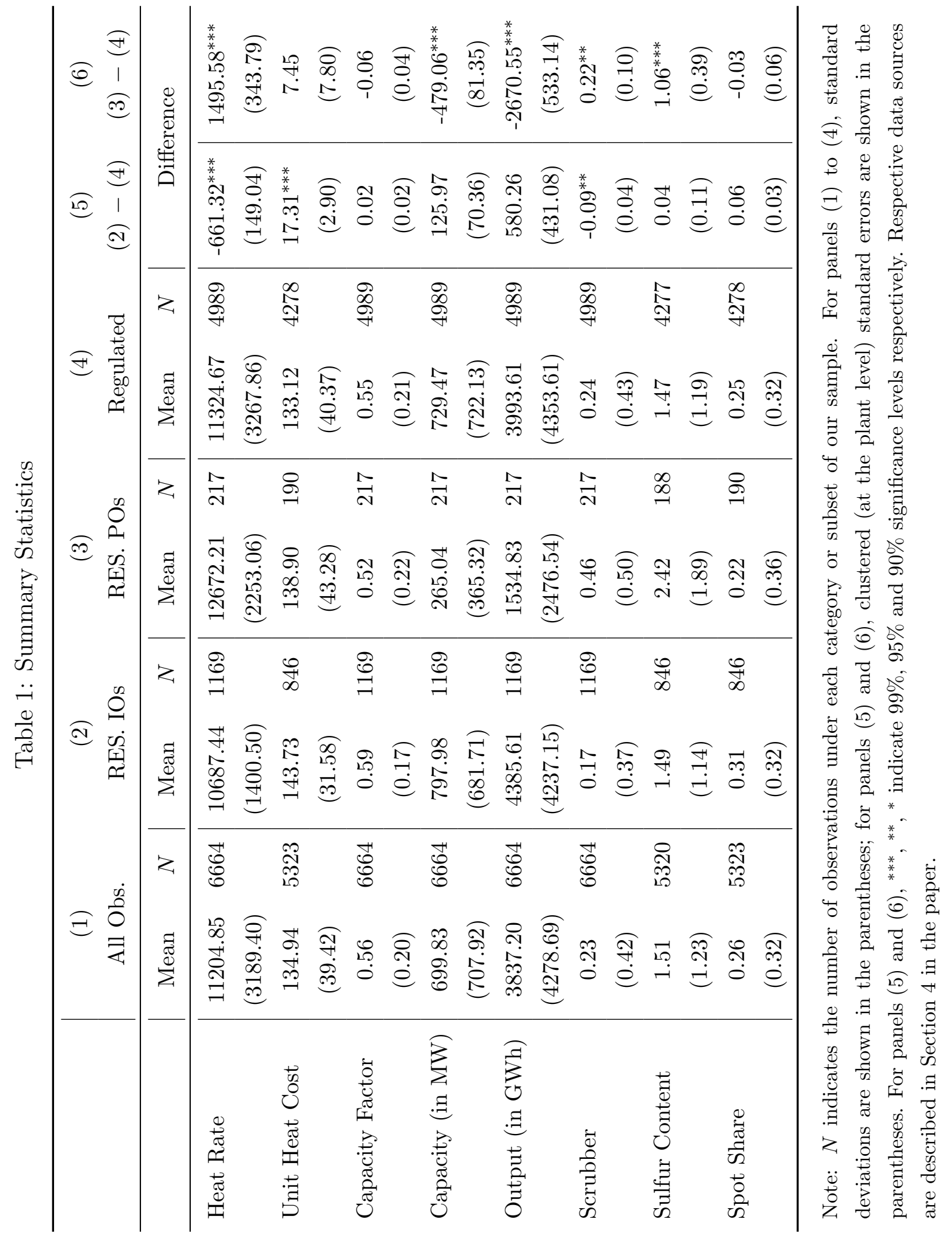




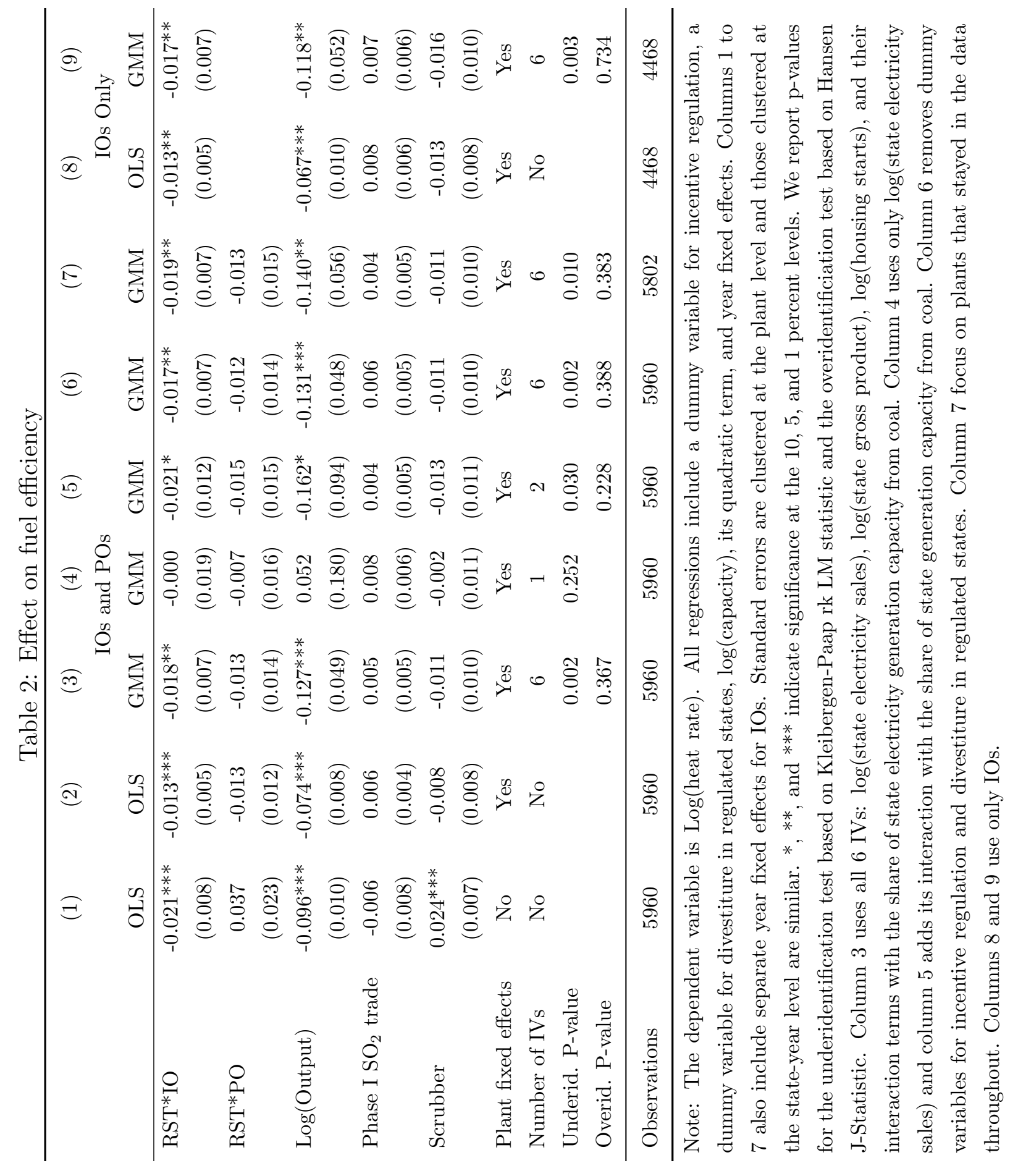




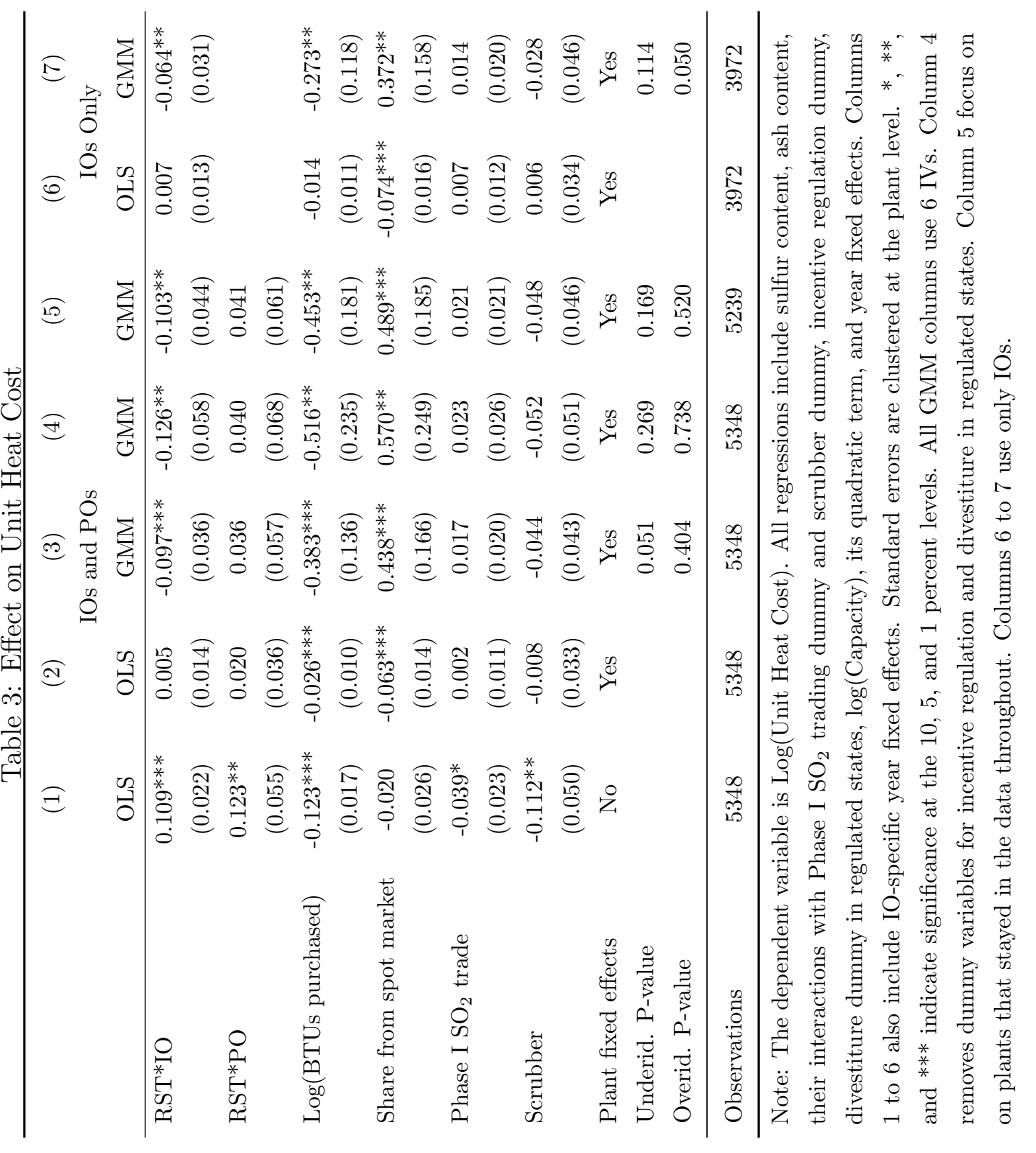


Table 4: Additional Robustness Checks

\begin{tabular}{|c|c|c|c|}
\hline Specifications & LawPass & FRW-RST & East Only \\
\hline \multicolumn{4}{|c|}{ Heat Rate Equation } \\
\hline \multirow[t]{2}{*}{$\mathrm{RST}^{*} \mathrm{IO}$} & $-0.016^{*}$ & $-0.021^{* * *}$ & $-0.013^{* *}$ \\
\hline & $(0.009)$ & $(0.008)$ & $(0.006)$ \\
\hline Underid. P-value & 0.016 & 0.002 & 0.000 \\
\hline Overid. P-value & 0.226 & 0.371 & 0.110 \\
\hline Observations & 5960 & 5960 & 3828 \\
\hline \multicolumn{4}{|c|}{ Unit Heat Cost Equation } \\
\hline \multirow[t]{2}{*}{$\mathrm{RST}^{*} \mathrm{IO}$} & $-0.123^{* *}$ & $-0.099^{* *}$ & -0.055 \\
\hline & $(0.056)$ & $(0.037)$ & $(0.034)$ \\
\hline Underid. P-value & 0.005 & 0.079 & 0.071 \\
\hline Overid. P-value & 0.856 & 0.317 & 0.180 \\
\hline Observations & 5348 & 5348 & 3400 \\
\hline
\end{tabular}

Note: All results are based on GMM estimation with plant fixed effects, IO-specific and PO-specific year fixed effects. "LawPass" uses LawPass $i t$ for the restructuring dummy, ruling out anticipatory effects from restructuring. "FRW-RST" includes an additional control for plants listed as "restructured" in Fabrizio et al. (2007), but not in our definition of restructuring. Fabrizio et al. (2007) label states as restructured as long as a hearing was held and a restructuring legislation was passed but the implementation of the legislation is not necessary. "East Only" considers plants in the eastern Census Regions of East North Central, East South Central, Middle Atlantic, New England, and South Atlantic. 


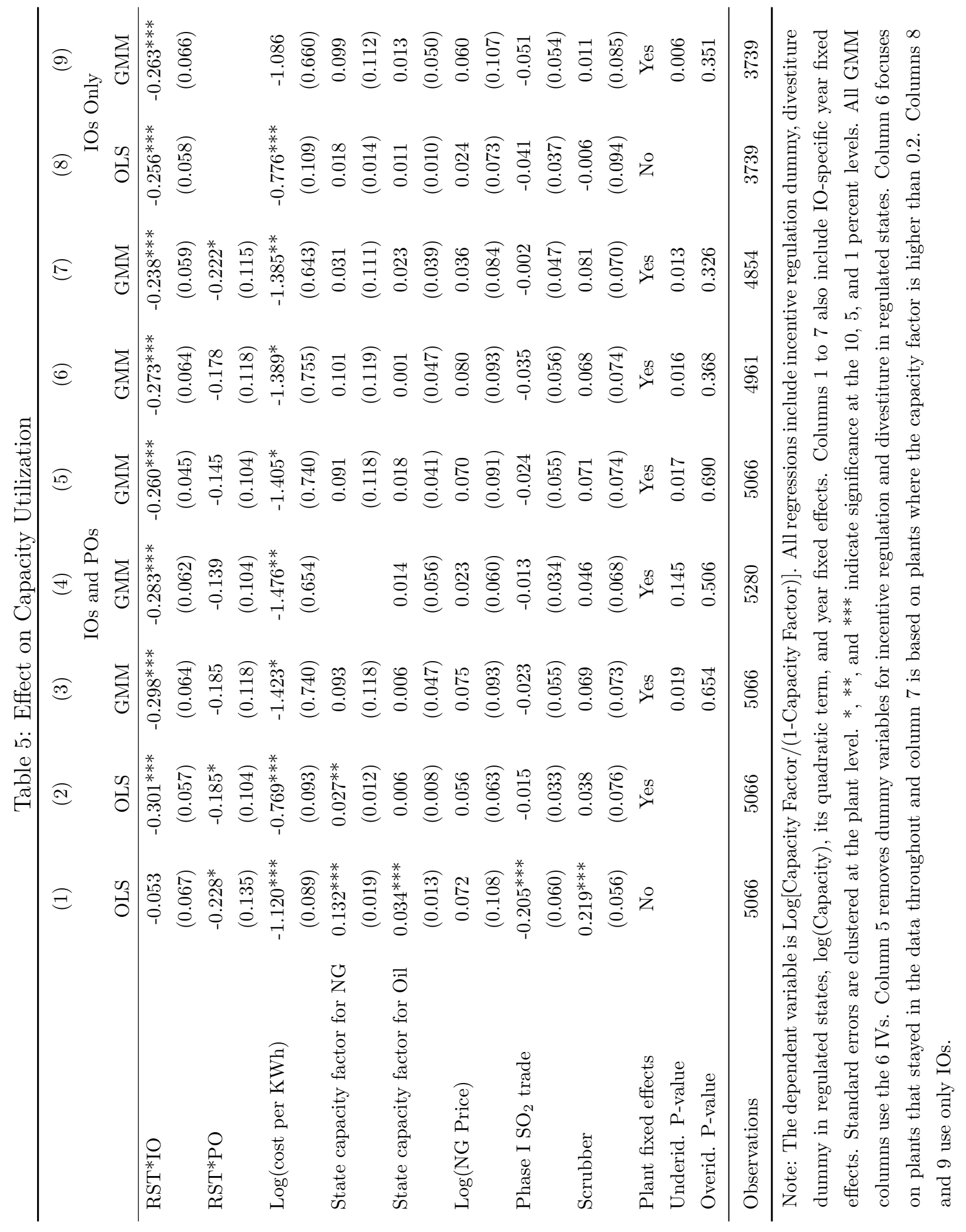


Table 6: Cost Savings and Environmental Impacts per Plant

\begin{tabular}{lcccc}
\hline Sources of Impacts & $\begin{array}{c}\text { Cost Savings } \\
\$ \text { mil. }\end{array}$ & $\begin{array}{c}\mathrm{SO}_{2} \\
\text { mill. ton }\end{array}$ & $\begin{array}{c}\mathrm{NO}_{X} \\
\text { mil. ton }\end{array}$ & $\begin{array}{c}\mathrm{CO}_{2} \\
\text { mil. ton }\end{array}$ \\
\hline From Heat Rate & 1.37 & 519 & 240 & 89,826 \\
From Coal Procurement & 5.12 & - & - & - \\
From Capacity Factor - Nuclear Replace & - & 1788 & 825 & 309,352 \\
From Capacity Factor - Nat. Gas Replace & - & 1774 & 591 & 153,232 \\
\hline & & & & \\
Combined Effect (Nuclear Replace) & 6.51 & 2,307 & 1065 & 399,178 \\
\% of Combined Effect & 11.65 & 7.55 & 7.55 & 7.55 \\
\hline & & & & \\
Combined Effect (Nat. Gas Replace) & 6.51 & 2,294 & 832 & 243,058 \\
\% of Combined Effect & 11.65 & 7.50 & 5.89 & 4.60 \\
\hline
\end{tabular}

Note: "Heat Rate" results are based on parameter from Table 2, column 3. "Coal Procurement" results are based on estimates from Table 3, column 3. "Capacity Factor" results are based on estimates from Table 4, column 3. "Nuclear Replace" results assume nuclear plant generation replaces reduced coal generation. "Nat. Gas Replace" results assume natural gas plant generation replaces reduced coal generation. "\% of Combined Effect" refers to the percentage share of the average annual totals accounted for by the "Combined" results. 


\section{References}

Bellas, Allen and Ian Lange, "The 1990 Clean Air Act and the Implicit Price of Sulfur in Coal," The B.E. Journal of Economic Analysis and Policy, 2007, 7 (1).

Borenstein, S., M. Busse, and R. Kellogg, "Career Concerns, Inaction, and Market Inefficiency: Evidence from Utility Regulation," Journal of Industrial Economics, 2012, 60 (2), 220-248.

Borenstein, Severin, James Bushnell, and Frank Wolak, "Measuring Market Inefficiencies in Californias Restructured Wholesale Electricity Market," American Economic Review, 2002, 92, 1376-1405.

Bushnell, James and Catherine D. Wolfram, "Ownership Change, Incentives and Plant Efficiency: The Divestiture of U.S. Electric Generation Plants," 2005. Center for the Study of Energy Markets WP 140.

Cicala, Steve, "When Does Regulation Distort Costs? Lessons from Fuel Procurement in U.S. Electricity Generation," 2012. Harvard University mimeo.

Cropper, Maureen L., Alexander Limonov, Kabir Malik, and Anoop Singh, "Estimating the Impact of Restructuring on Electricity Generation Efficiency: The Case of the Indian Thermal Power Sector," 2011. NBER Working Paper, \#17383.

Davis, Lucas W. and Catherine D. Wolfram, "Deregulation, Consolidation, and Efficiency: Evidence from U.S. Nuclear Power," 2012. forthcoming, American Economic Journal: Economy Policy.

_ and Lutz Kilian, "The Allocative Cost of Price Ceilings in the U.S. Residential Market for Natural Gas," Journal of Political Economy, 2011, 119 (2), 212-241.

Dean, J. Craig and Scott J. Savage, "Market Restructuring, Competition and the Efficiency of Electricity Generation: Plant-level Evidence from the United States 1996 to 2006," The Energy Journal, 2013, 34 (1).

Douglas, Stratford, "Measuring Gains from Regional Dispatch: Coal-Fired Power Plant Utilization and Market Reforms," The Energy Journal, 2006, 277 (1), 119-138. 
Fabrizio, Kira, Nancy Rose, and Catherine D. Wolfram, "Do Markets Reduce Costs? Assessing the Impact of Regulatory Restructuring on US Electric Generation Efficiency," American Economic Review, 2007, 97 (4), 1250-1277.

Fowlie, Meredith, "Emissions Trading, Electricity Restructuring, and Investment in Pollution Abatement," American Economic Review, 2010, 100 (3), 837-869.

Galiani, Sebastian, Paul Gertler, and Ernesto Schargrodsky, "Water for Life: The Impact of the Privatization of Water Services on Child Mortality," Journal of Political Economy, 2005, 113, 83-119.

Hortaçsu, Ali and Steven L. Puller, "Understanding strategic bidding in multi-unit auctions: a case study of the Texas electricity spot market," RAND Journal of Economics, 2008, 39 (1), 86-114.

International Energy Agency, "Power Generation from Coal: Measuring and Reporting Efficiency Performance and $\mathrm{CO}_{2}$ Emissions," 2010.

Knittel, Christopher, "Alternative Regulatory Methods and Firm Efficiency: Stochastic Frontier Evidence the US Electricity Industry," The Review of Economics and Statistics, $2002,84(3), 530-540$.

Laffont, Jean-Jacques and Jean Tirole, A Theory of Incentives in Procurement and Regulation, MIT Press, 1993.

Mansur, Erin, "Upstream Competition and Vertical Integration in Electricity Markets," Journal of Law and Economics, 2007, 50 (1), 125-156.

_, "Measuring Welfare in Restructured Electricity Markets," Review of Economics and Statistics, 2008, 90 (2), 369-386.

Mueller, Nicholas, Robert Mendelsohn, and William Nordhaus, "Environmental Accounting for Pollution in the United States Economy," American Economic Review, 2011, 101 (5), 1649-1675.

Newbery, David M. and Michael G. Pollitt, "The Restructuring and Privatisation of Britain's CEGB - Was It Worth It?," Journal of Industrial Economics, 1997, 45 (3), 269-303. 
Olley, Steven and Ariel Pakes, "The Dynamics of Productivity in the Telecommunications Equipment Industry," Econometrica, 1996, 64, 1263-1297.

Syverson, Chad, "Market Structure and Productivity: A Concrete Example," Journal of Political Economy, 2004, 112 (6), 1181-1222.

White, Matthew, "Power Struggles: Explaining Deregulatory Reforms in Electricity Markets," Brookings Papers on Economic Activity. Microeconomics, 1996, pp. 201-250.

Wolfram, Catherine D., "Measuring Duopoly Power in the British Electricity Spot Market," American Economic Review, 1999, 89 (4), 805-826.

Zhang, Fan, "Does Electricity Restructuring Work? Evidence From the U.S. Nuclear Energy Industry," Journal of Industrial Economics, 2007, 55 (3), 397-418. 